\title{
The Past, Present, and Future of the Chinese Home An Architectural Study of the Relationship Between Politics, Culture, and Domestic Space
}

By | Tina Huang | 黄维钰

A thesis submitted to the Faculty of Graduate and Postdoctoral Affairs in partial fulfillment of the requirements for the degree of

Master in Architecture

Carleton University, Ottawa, Ontario

C2021TinaHuang 


\section{ABSTRACT}

his thesis analyzes the oscillating cause and effect between State, citizen,
and architecture by studying the relationship between politics and domestic spaces in China. It explores the development of China from the beginning of the twentieth century through the present and into a speculative future to argue that wider socio-political changes are reflected in the detailed and intimate spaces of the home, and conversely, that the home can act as an agent of political resistance. The timeline in question represents a unique and tumultuous era in the development of modern China, one which dramatically changed the way people in China built their homes, and in turn, lived their lives. By imagining a speculative future condition in which China has undergone another major political and cultural shift, this thesis will consider the past in order to propose a speculative trajectory for the future of domestic Chinese architecture. 


\section{ACKNOWLEDGEMENTS}

I want to firstly thank my advisor Natalia for your patience and constant support during this past year, your encouragement throughout the writing of this thesis has been invaluable.

To the staff and faculty at the Azrieli School of Architecture and Urbanism, thank you for making the last six years so wonderful. The guidance and support from everyone has been crucial to my educational growth.

To my friends, the new ones I've made and the old on who have always been with me, thank you for your unwavering support, even when you had no idea what I was doing.

I want to thank my parents; I would not have been able accomplish this degree had they not gotten on that plane to Canada 18 years ago. Special thanks to my mom who became my translator for many of the Chinese text I came across during my research.

Lastly I want to thank Jimmy, for believing in me from the very beginning, and reassuring me every step of the way. Thank you for being by editor, my sounding board, and confidant. We did it! 


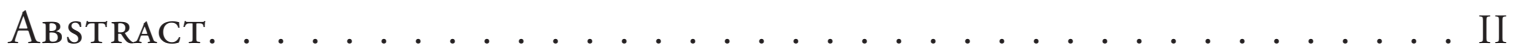
ACKnowledgements . . . . . . . . . . . . . . . . III TABle of Context . . . . . . . . . . . . . . . . IV List of IMAGES . . . . . . . . . . . . . . . . . . . . . . VIII

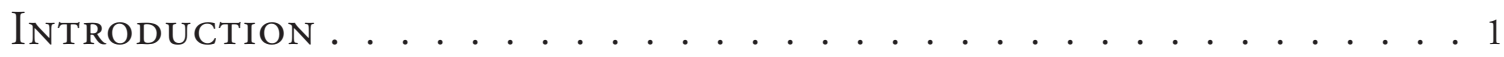
PT I | THE Historic RELATIONSHIP BETWEEN THE HOME AND POLITICAL REGIMES: FROM MAO TO THE PRESENT

I. The Siheyuan: Post-Dynastic Period and the ascension of the Chinese Communist Party $[1911-1949] \ldots \ldots \ldots \ldots$ II. The Commune and Danwei: The Collectivization of Family Life during the Maoist

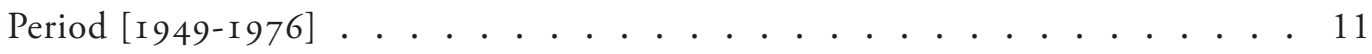

III. The Apartment: Chinese Society Today, and Their Loss of Cultural Identity [1976-Present Day $\ldots \ldots \ldots \ldots$. . . . . . . . . . . . 17

IV. Architectural Resistance and the Governments Response

[1911-Present Day $\ldots \ldots \ldots \ldots \ldots$

PT $2 \mid$ Methodology . . . . . . . . . . . . . . . . . . . 32

PT 3 | A Catalogue of Space Within the Home

I. Place of Prayer and Reflection . . . . . . . . . . . . . . . . . . . . 39

II. Place of Dinning . . . . . . . . . . . . . . . . . . . . . . 5 52

II. The Bedroom . . . . . . . . . . . . . . . . . . . . . . . 64

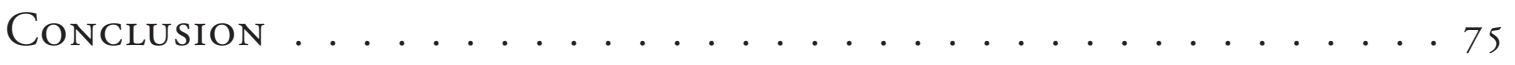

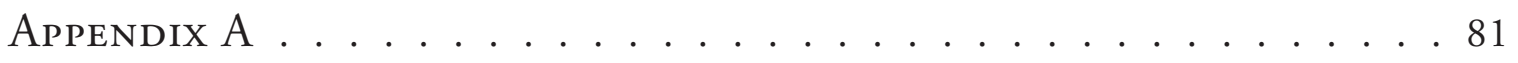

Image Source . . . . . . . . . . . . . . . . . . . 82

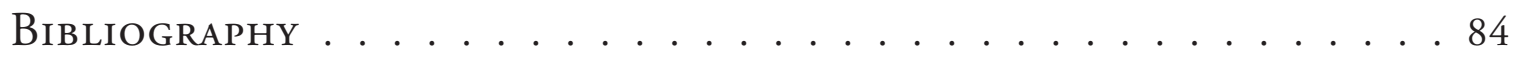


[Figure 1.1] The Ideal City Layout

[Figure 1.2] i 87 i City Map of LangZhong

[Figure 1.3] Fengshui Drawing of Zhifeng Village

[Figure 1.4] Evolution of the North Courtyard Home

[Figure 1.5] Evolution of the Southern Courtyard Home

[Figure 1.6] Hierarchy of the Human Body Represented in the Domestic House

[Figure 1.7] Spatial and Hierarchical Organizations of the Courtyard House

Figure 1.8] Official Portrait of Mao Zedong

[Figure 1.9] Floor plan of a multifunctional canteen, The Panyu People's Commune GUANGDONG, I959

[Figure 1.10] The proposal for the apartment building, Suicheng People's Commune, Xushui Hebei, i958

[[Figure 1.11] Perspective drawing of a corner of Beiyangcun

[Figure 1.12] Five Story apartment buildings in Beijing (i 999)

[Figure 1.13] Internal layout of a STANDARDized Danwei ReSidential unit

[Figure 1.14] Propaganda from the Cultural Revolution

[Figure 1.15] Photography of Deng Xiaoping

[Figure 1.16] Enjili residential buildings, Beijing, i 993

[Figure 1.17] Housing development in Ordos, Inner Mongolia

[Figure 1.18] Рhotography of Xi Jinping

[Figure 1.19] CCTV Headquarters

[Figure 1.20] Guangzhou Opera House

[Figure 1.21] Shanghai skyline, featuring the Shanghai Tower

[Figure 1.22] Shanghai in the ig3os

[Figure 1.23] The Split House

[Figure 1.24] The Split House courtyard space

[Figure 1.25] Eiffel Tower in China

[Figure 1.26] Thames Town 
[Figure 1.27] Ju'er Hutong COURTyard homes

[Figure 1.28] Ju'Er Hutong interior Courtyards

[Figure 1.29] Before and after installation of the plugin system by PAO

[Figure 2.1] Map of Vernacular housing typology

[Figure 2.2] Common plan of China's typical home: three bays and five PURlin STyle

[Figure 2.3] Diagrammatic DeVelopment of NeW GRid System

[Figure 2.4] Diagrammatic drawing of spatial patterns in Chinese vernacular DWELLINGS

[Figure 3.1] Place of Prayer and Reflection: The Main Hall

[Figure 3.2] Place of Prayer and Reflection: The Communal Space

[Figure 3.3] Place of Prayer and Reflection: The Residences

[Figure 3.4] Place of Prayer and Reflection: Urban Apartment

[Figure 3.5] Place of Prayer and Reflection: Rural Home

[Figure 3.6] Place of Prayer and Reflection: The Multi-Faith Rooms

[Figure 3.7] Place of Prayer and Reflection: Redefining The Space of Prayer

[Figure 3.8] Place of Dinning: The Courtyard

[Figure 3.9] Place of Dinning: The Canteen

[Figure 3.10] Place of Dinning: The Single Individual

[Figure 3.11] Place of Dinning: The Migrant Parents

[Figure 3.12] Place of Dinning: The Family Back Home

[Figure 3.13] Place of Dinning: The Virtual Family

[Figure 3.14] Place of Dinning: The Surrogate Family

[Figure 3.15] The Bedroom: The Female’s Private Bedroom

[Figure 3.16] The Bedroom: The Female's Residence on the Commune

[Figure 3.17] The Bedroom: The Roommates

[Figure 3.18] The Bedroom: The Migrant Parents

[Figure 3.19] The Bedroom: Shared Space

[Figure 3.20] The Bedroom: Reclaiming Individual Privacy

[Figure 3.21] The Bedroom: The Unit 


\section{INTRODUCTION}

rchitecture does not exist in isolation. Works of architecture are the product
of the political and cultural context of the place and time in which they are designed. Conversely, it is equally true that works of architecture can exert an influence on those same contexts. This thesis is founded on notion that that modest domestic architecture is more truly reflective of a society's sociopolitical, economic, and philosophical identity than any elaborate monumental structure that has been designed to project those things. Throughout history, major changes in a collective social consciousness have shifted very slowly, often taking generations to truly take hold within a society. Few examples can be found in the past century of such a dramatic, top-down, shift in cultural attitude than that imposed by the Communist Party of China. Within a single generation, shifting political ideologies had substantially altered people's perception of home, family, and spirituality.

During this time domestic space became highly politicized, as 
the government transformed the family home into a tool of communist expansion. Meanwhile, domestic architecture would later be the focal point of experimentation and innovation for architects trying to reestablish a "Chinese Architecture."In this way domestic space is used both as a means of control and an act of resistance.

The inspiration to study this era for my thesis is twofold. First, I wanted to learn more about it for myself. I was born in China and spent the first 7 years of my life there, before immigrating to Canada. Growing up, I gathered little bits of information about Chairman Mao and the Cultural Revolution, however I never learned the full history or understood its implications. Second, in my experience Asian history is often overlooked in Canadian education, owing to this country's European roots. This is especially apparent in architectural studies. The Asian perspective is nearly non-existent alongside the very Eurocentric history and theory of architecture that we have studied. With my thesis I hope to open a dialogue regarding the role of an Asian context in the study of architecture. As such, my thesis book features an extensive historical account of 20th Century China and the professionalization of architecture. This historical survey is meant to provide the reader with the context necessary to analyze the intersections of politics, culture, and domestic architecture in the Chinese home and to understand how each of these may affect the others.

This cultural and political history will be explored through a series of diagrammatic timelines, from the end of the Dynastic Era in 1912 to after the Cultural Revolution in 1976, documenting the major events and interwoven facets of China's architecture, politics, and domestic familial life. Additionally, a catalogue of detailed typological drawings will present a generalization of various significant spaces inside the home spanning from traditional domestic architecture found during the dynastic periods to the collectivist communes 
of the Cultural Revolution, up until the eclectic present. These drawings seek to fill in the gaps in existing documentation by referencing various descriptive accounts of quotidian life which compliment and enrich extant drawings. I then apply the knowledge attained form this exercise to project what domestic spaces may look like in an imagined, speculative future condition. By examining how hierarchy is constructed through space and aesthetic codes within these various spaces, these graphic analyses will serve to establish a deeper understanding of how domestic space responds to and challenges prevailing socio-political ideology. My intention is that this thesis will call attention to the very important responsibility we as architects have to not only respond to the political and cultural context within which we are designing, but to critically examine it and identify the opportunities we have to challenge the status quo in the pursuit of a more just and equal society. 

AND POLITICAL REGIMES: FROM MAO TO THE PRESENT 


\section{[I] The Sibeyuan Post-Dynastic Period and the ascension of the Chinese Communist Party [1911-1949]}

The existing hierarchy of space in China, established throughout the Dynastic Era, reinforced the evolution of power as the country underwent dramatic and consequential changes. Since around 2070 BCE, China followed a Dynastic tradition and had been ruled by a series of Emperors ${ }^{1}$. Apart from the religious structures and monumental design of the Imperial City, the architecture during the Dynastic rule revolved largely around its gardens and parks, employing the virtues of yin and yang within the Chinese philosophical system. There was no such profession as architect in China during the Dynastic eras. There were builders and there were labourers, but there was no formalized system of education or professional certification. ${ }^{2}$ In the second half of the nineteenth century, Western architectural styles began to appear in major Chinese cities owing to the Opium War of 1842. The influence of the West however, was contained to large-scale architecture and urban centres, but did no influence common family home.

The beginning of the twentieth century saw the fall of Dynastic tradition with the official dissolution of the Qing Dynasty in 1911. The resulting political vacuum was filled by the new Nationalist Party of China, the Kuomintang, and the Republic of China was established. Urban renewal was a core policy of the new Republican Regime in the late 1920s, however mainly focused within the larger cities. It was also by the 1920 s, the architect emerged as a recognized 
profession and the first architecture schools were opened. ${ }^{3}$ The government actively encouraged new architectural pursuits in major Chinese cities and requested prominent architectural professionals to contribute their designs to modernize urban China. This new policy enticed many architecture students returned to China after studying abroad in the hopes of developing a modern Chinese architecture that could be a part of the global discourse. The villages in rural China experienced no such interference from the government in the first half of the twentieth century, and so carried on in a more or less traditional way; as agriculturally self-sufficient peasant economies. As a result many of these dwellings were built and designed by the residents themselves or their ancestors before them, and expanded as the family grew in size and/or wealth.

The hierarchy found in most traditional domestic spaces throughout China is based on pre-existing doctrines of Confucianism. ${ }^{4}[F I G .1 .1-1.3]$ In the absence of any official architectural regulations, houses were built according to the principles of Confucian ideals of family. ${ }^{5}$ Each home represented a specific family, and each member of that family was spiritually tied to the physical structure of the home. The home was a place where one found comfort, protection, security, and support as well as care in their old age. Multiple generations lived together in one house, functioning as a single economic entity, relying on the pooled efforts of its members for life's basic needs. The structure of relationships formed on both the inside and the outside of the home was based heavily on a sense of hierarchy, a

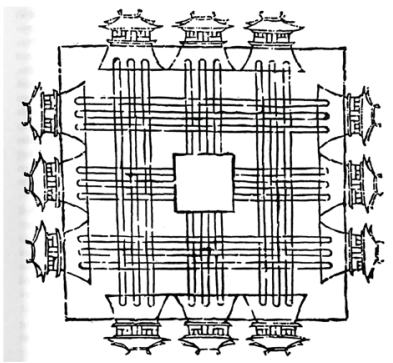

[FIGURE 1.1] Representation of the ideal urban city.

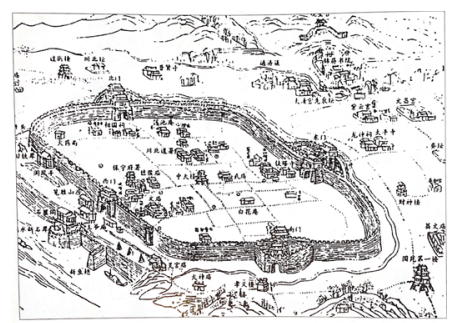

[FIGURE 1.2] 1871 city map of Langzhong, Sichuan. The walls surrounding the settlement are said to date to the seventh century. The city of Langzhou is said to exemplify the one of the best examples of fengshui of any Chinese city.

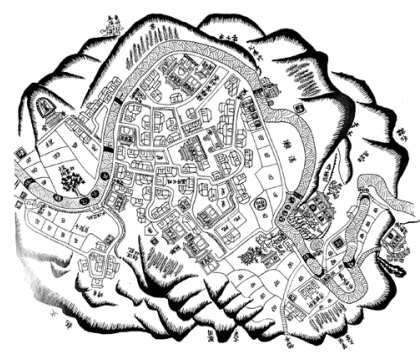

[FIGURE 1.3] Fengshui drawing of Zhifeng Village, Jiangxi Province. The mountains, bodies of water, graves and important structures are named as part of an auspicious composition. The embracing ranges on the sides are considered analogous to a protecting Azure Dragon on the east and a White Dragon on the West. 
carry-over from the Dynastic past. Within the home there were three significant power structures base on patriarchal systems: the patrilineal relationship between the father and the eldest son, the traditional patriarchal relationship between husband and the wife, and the mentoring relationship between elder brother and the younger brother. This social structure was recognized throughout China for many millennia and informed the basic principles of Chinese home design. The following will explain how these abstract ideas translate into concrete spatial relationships in domestic spaces.

The construction and design of domestic homes were subject to three things: geography, the availability of natural materials, and the wealth of the family or individual. Builders used materials that ranged from local soils, plant materials, and timber to fired bricks, carved stones, and rare timber, with every builder favouring certain structural techniques and principles. The largest visual difference in Chinese homes [FIGURE 1.4] Spatial representation of the evolution of the courtyard in Northern are based on their geographical locations. China's climate can houses. Houses in the north are larger in floor coverage, In order to take advantage of solar range from the severe cold temperatures of the North to the hot tropics found in the South, requiring a diverse array of building styles and construction methods. Homes in the North typically covered more ground area in order to maximize solar heat gain [FIG.1.4], while homes in the South were much more insular and featured more numerous courtyards and skywells to decrease heat gain [FIG.1.5]. While there is no single style that can be called "a Chinese house," it is possible to point $\begin{aligned} & \text { [FIGURE } 1.5] \text { Spatial representation of the } \\ & \text { evolution of the courtyard in Southern houses. }\end{aligned}$ to a set of remarkably similar elements shared by many-if 
not most-houses, whether simple or grand. The dwellings were generally one, sometimes two storey structures, enclosed and inward looking while still being "symmetrically balanced, ritually centred, and hierarchically structured." ${ }^{\prime}$ Open spaces in the form of courtyards and skywells were found in endless varieties. These negative spaces were an important element in the spacial layout of a fully formed house. The number of courtyards a home was able to have come to be an indication of that family's wealth and prosperity, and while the resources required to achieve this could not always be attained at the outset, homes were assembled piecemeal and the courtyards slowly would be formed.

The qualities of Confucian architectonics emphasizes the importance of hierarchical order, central axis and the control of spatial organizations through symmetry. ${ }^{7}$ [FIG. 1.6] The spacial order of the archetypal one-yard courtyard home is reflective of the social relationships held up by the Confucian moral order and the Dynastic patriarchal society, the spatial syntax of the home subtly perpetuates the social hierarchy within the family. These spatial hierarchies are further exemplified by the five Chinese cardinal directions, east (dong), south(nan), west( $x i)$, north(bei), and centre(zhong), with greater emphasis placed on the fertility of the south. Representing the nucleus of the house, the Main Hall was symbolic of the family's unity, continuity and power as a corporate unit. Located on the northern most section of the house, it is seen as the most spiritual room, and is often represented by the heightened formality of the

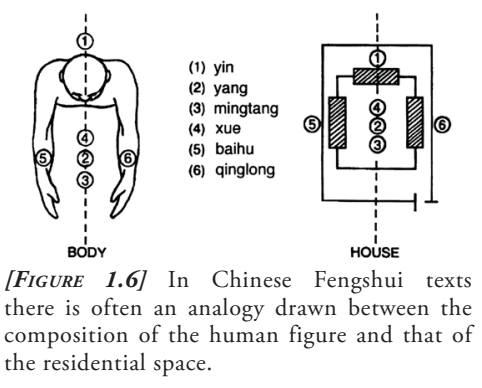
the residential space. 
space. Placement of hierarchical space is generally laid out in relation to the Main Hall, with senior members of the family sleeping in bedrooms directly connected to the hall. Socially, these members were generally the overseer of the family and that location allowed them to be in command of the internal courtyard and adjacent rooms. The rest of the family were housed in rooms flanking east and west of the courtyard. The rooms closest to the main entrance on the southern wall typically serve more public functions, or servants quarters, creating a transitional space between the public and the private realm. Spaces for women in the family were typically separate from the men and placed in more private portions of the home, enforcing the separation through specialized passageways and entrances. ${ }^{8}$ With this distribution of space, each member was visible within the hierarchical order and an individuals behaviour was scrutinized through the transparency of the open courtyard formation. ${ }^{9}$ [FIG.1.7]

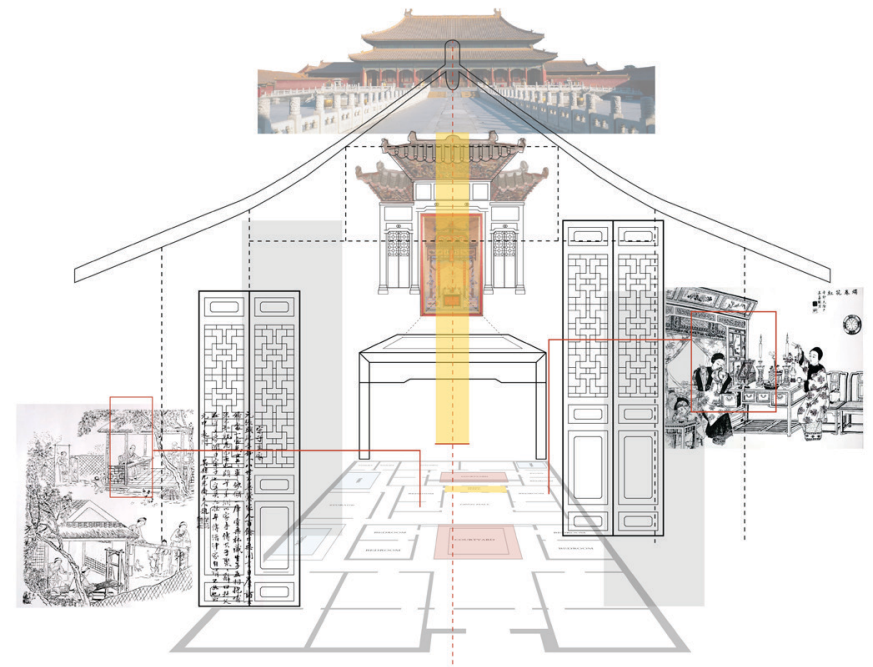


The courtyard house remained the norm for most Chinese families up until mid-twentieth century politics began to infiltrate the domestic realm. In the same year that the KMT established control over China, an opposing party was also being formed, The Communist Party of China. Unsatisfied with the Nationalist policies and the governing style of the organization, they sought to establish China as a Communist State, taking their lead from the soviets to the North. By 1949, the Communist party had defeated the Nationalists and Soviet Communist ideals began to infiltrate popular discussion and political discourse in China, architecture shifted to a more utilitarian, Soviet-inspired style of design. It is at this moment that much of China's domestic architecture begins to reflect the Authoritarian style.

\section{Endnotes}

1 Yun Kuen Lee, "Building the Chronology of Early Chinese History," Asian Perspectives 41, no. 1 (2002): 15.

2 Bing Wang, "Structuring of the Architectural Profession in Modern China" (dissertation, 2004), 13.

3 Wang, "Architectural Profession", 13-15

4 There is archaeological evidence showing that the emphasis on orientation, layout and symmetry were present in Chinese Houses tracing back to the antiquity. Patricia Buckley Ebrey, "House Architecture," A Visual Sourcebook o Chinese Civilization (University of Washington), accessed February 2, 2021, https://depts. washington.edu/chinaciv/home/3intrhme.htm.

5 These same Confucianist principles of spatial hierarchy in design are found within governmental architecture during the Dynamic era. The Imperial Palace is essentially designed with the same spatial layout as a courtyard home.

6 Ronald G. Knapp, Chinese Houses: the Architectural Heritage of a Nation (Tuttle, 2005), 70.

7 Joseph Needham, Wang Ling, and Gwei-Djen Lu, Science and Civilisation in China, vol. 4 (London: Cambridge University Press, 1971).

8 Knapp, Chinese Houses, 27

9 Knapp, Chinese Houses, 70 


\section{[II] The Commune and Danwei \\ The Collectivization of Family Life during the Maoist Period [1949-1976]}

Following the founding of the People's Republic of China in 1949 under the leadership of Chairman Mao Zedong [FIG.1.8], the government set forth to re-stabilize the country. In a radical attempt to propel the country's political and economic standing forward on the world stage, Mao sought to transform the agrarian state of the country, characterized by the economy's dependence on the production and maintenance of crops and farmland, into one geared towards industrialization and progressive development. His adopted ideals of collectivism,

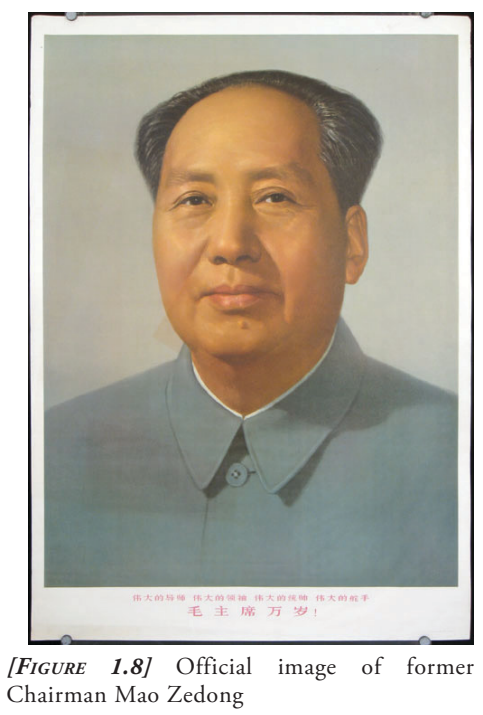
influenced largely by the previous century's Marxism, was the foundation of his own political philosophy, Maoism. To the people of China this collectivist concept emphasized similar principles to Confucianism, which were embedded into the very traditions Mao sought to abolish with the Cultural Revolution. The early teachings of Confucius were fundamental to Mao's success, by introducing the State as a larger component of the family, later altering the family dynamic through architectural, hierarchical, and environmental changes in the family home. If the Cultural Revolution can be said to have had any level of success, a notion which is itself contested, it is due in large part to the effectiveness of Mao's transmutation of traditional Confucian principles into his new Collectivist ideology. It is with that transference that Mao was able to gain the enthusiastic support of the Chinese people to enact the Revolution which would permanently alter the image of domestic architecture 
in China. This process began with the first Five Year Plan, which set ambitious targets for infrastructure and production, particularly in heavy industries, would also radically change the nature of interpersonal relationships, peoples' associations to home, and the overall patterns of everyday life.

Following the 'success' of the this Five Year Plan, "a new organizational form which integrated industry, agriculture, trade, education and military affairs" ${ }^{1}$ was being established in the countryside. Traditional villages were being replaced by modern residential clusters called Communes. These were categorized as a higher-level collectives became the amalgamation of the smaller co-operatives established in the beginning of the decade. Labelled as 'production teams' they did away with compensation for anything other than labour and with that eliminated the economic inequality within the villages. ${ }^{2}$ These communes were typically built by the members themselves, using both local materials and government provided resources. The aim was to revolutionize the traditional social institutions by collectivizing family life. Communal services such as public canteens, nurseries, kindergartens, and public homes for the aged were considered essential to achieve these goals [FIG.1.9]. The Party sought to abolish the single family paradigm, communal food, laundry and childcare were provided to free women from the mundanity of housework and instead allow them to contribute to general industrial Panyu Peoples Commune, Guangdong, 1959 production. ${ }^{3}$ Unmarried members of the family were separated by the sexual binaries of female and male and housed in different buildings, further weakening the family unit. Single adults

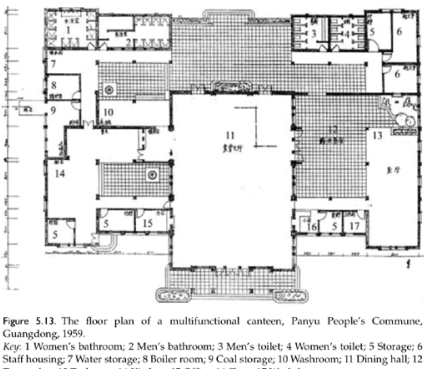


were assigned into dormitory rooms, usually shared by three to four individuals [FIG.1.10], the elderly stayed in retirement homes and the young children were brought to separate spaces such as the kindergartens or state schools. ${ }^{4}$ The previous focal points for rural life, such as ancestral halls, temples, and local markets, gave way to modern institutions of collective canteens, schools, and co-op shops. Accessory dwellings which provided shelter for extended kin were abandoned, instead their functions were divided into separated institutes. In every way, the commune system hoped to proclaim an end to the peasantry, its institutions and its long-established way of life. ${ }^{5}$ This was achieved in no small part, by abolishing the spatial existence of the nuclear family home.

Simultaneously there was an intensification geared towards the urban core; Similar to the communes found in rural China, urban centres had various Danweis. The Danwei was not merely a type of workplace, but a long-standing and multifaceted institution embedded in the larger sociopolitical system [FIG.1.11]. The Danwei, by combining economic, political, and social functions, “...integrates workplace, residence and social facilities in close proximity within one or several walled compound(s);"6 most daily affairs could be conducted without ever leaving the unit. Housing in the work unit was simple and utilitarian, dormitories for single workers

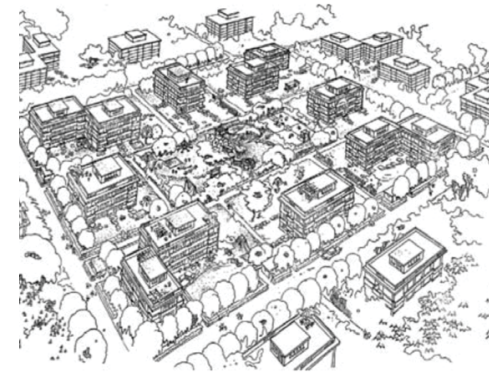
[FIGURE 1.11] Perspective view of the Beiyangcun residential block and apartments for families, housed in two to six-story high buildings erected in an orderly row. However, the symmetrical and formal composition of these plans were achieved at the expense of sunshine and ventilation for some housing units. ${ }^{7}$ 
Similar to the communes, dormitories were separated by gender, and occupied instead by four to eight workers in a bunk-style room. Many facilities are removed from these private rooms: “...common restrooms are provided on each floor, there are no kitchens, dining rooms or shower rooms; people are expected to eat in unit canteens and take showers in public bathhouses." The apartments provided for families ranged from one to three bedrooms depending on the size of the families, often having centralized bathrooms and communal kitchens to be shared by several families. The monotonous activities of life functioned within the confines of the units walls, workers often doing the same job from graduation to retirement. ${ }^{9}$ Many of the housing designs during this period were almost identical throughout the country, lacking the relationship to local, traditional, or vernacular characteristics [FIG.1.12-1.13]. Every Danwei was responsible for the their members and reported their activities, this structure inhibited, although did not entirely prevent, large scale oppositions of regime. This system of surveillance

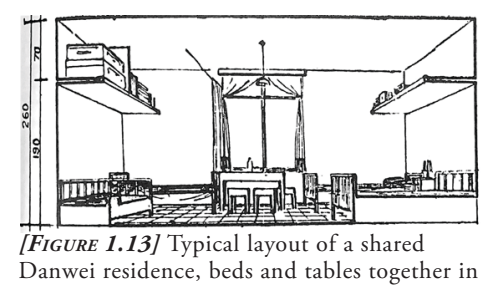
and overt power over their personnel remained one of the most can open concept space.

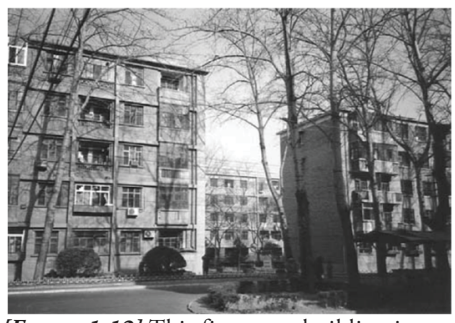

[FIGURE 1.12] This five-story building in Beijing use to be the residential compound for workers at the nearby Danwei potent weapons in the Danwei's arsenal of political controls.

By 1957, the elimination of private enterprises marked the end of the nationalization process under communist leadership. ${ }^{10}$ This policy prompted the eradication of private architecture practices and later produced design principles that were implemented to better reflect the revolutionary spirit of the country. Domestic architecture during this period remained relatively unchanged, as the Communes and Danwei continued to spread across China. The grand and monumental 
architecture, however, underwent significant changes. During his time in power, Mao used the grandiosity of space to exemplify power and his presence in these spaces to demand respect. ${ }^{11}$

Despite his success at inspiring admiration and loyalty, the Great Leap Forward was a catastrophic failure, resulting in a famine that swept the nation and caused the deaths of tens of millions. ${ }^{12}$ The next five year plan was another sociopolitical campaign that would be known as the The Great Proletariat Cultural Revolution. During this time many buildings and structures were torn down with no regard for documentation, and any scholarly works examining the traditional styles were censored and blocked from publishing by a government which prioritized radical progressivism.

Since the initial Five Year Plan, the development of domestic architecture in China saw no substantial shift, and [FIGURE 1.14] Proclamations and bulletins [FIGURE 1.14] Proclamations and bulletins Danwei had been established as the norm across China and Mao, and called for an end to the violence throughout the years their numbers have only multiplied.

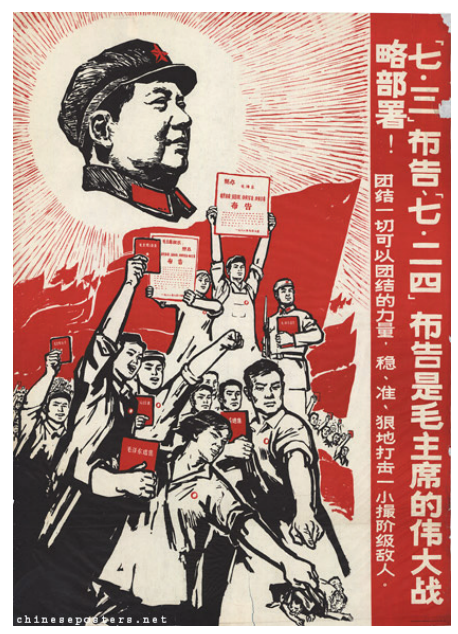
between the different factions in the Cultural Revolution, and for the return of weapons seized from the PLA (People's Liberation Mao's collectivist ideals sought to further separate the ideals of individualism and Confucianism from the sentiments of Chinese citizens, and aimed to only strengthen the Maoist philosophy [FIG.1.14]. This way of collectivist living and the idolization of the party continued until the death of Mao in 1976, his death brought forth new opportunities of change by the $\mathrm{CPC}$ and that change would be more reflective of China today. 


\section{Endnotes}

$1 \quad$ Duanfang Lu, Remaking Chinese Urban Form Modernity, Scarcity and Space, 19492005 (Abingdon: Routledge, 2011). 101.

2 There were approximately 53,000 communes in China, 170,000 peasants households in the communes, and 90,000,000 acres of arable land under the control of communes at the height of their existence.

"The Commune System (1950s)," Asia for Educators, accessed March 23, 2021, http:// afe.easia.columbia.edu/special/china_1950_commune.htm.

Patricia Buckley Ebrey, The Cambridge Illustrated History of China, Second (New York, NY: Cambridge University Press, 2010), 232.

3 Lu, Remaking Chinese Urban Form Modernity, Scarcity and Space. 107.

$4 \quad$ Lu, Remaking Chinese Urban Form.116.

$5 \quad \mathrm{Lu}$, Remaking Chinese Urban Form.118.

6 Lu, Remaking Chinese Urban Form. 48.

$7 \quad$ Charlie Q. L. Xue, Building a Revolution: Chinese Architecture since 1980 (Hong Kong: Hong Kong University Press, 2006), 88.

8 Lu, Remaking Chinese Urban Form. 62.

9 Ebrey, History of China, 322.

10 Wang, Architectural Profession in China,108.

11 This is seen by the announcement of "national celebration projects" built to celebrate the tenth anniversary of the Republic "to test the level of productivity achieved in socialist China... and went to answer with actions and facts...those who doubt that we can build a modern nation" (Wan Li, Deputy Mayor of Beijing). These projects were to be 10 buildings designed by individuals from the Beijing Institute of Architectural Design, built to a style that was the amalgamation of modernism, socialism and international style. They would be known as the Ten Grand Buildings, built to be monuments that embodied the strength of and capability of the Republic. This plan was aimed at transforming Beijing into a major capital city that could compete with London or Washington, DC. This new architectural style later came to dominate the design of public buildings in most large cities. The development of these buildings and the establishment of ceremonial public space further solidified Mao's vision of a new modern China and established him as a man of great power.

12 Wolfram Eberhard, A History of China, (Berkeley and Los Angeles, CA: University of California Press, 1950), 332-335. 


\section{[III] The Apartment \\ Chinese Society Today, and Their Loss of Cultural Identity [1976-Present Day]}

In 1978, two years after the death of Mao, China began opening its economy to the global market for the first time in since the PRC was established in 1949. Following the announcement of China's "Opening Up" or "Economic Reform," the country began to rapidly advance in new directions. Under new leadership the CPC turned away from the radical forms of collectivism and class struggle prevalent under Mao and abolished many of the socialist central planning

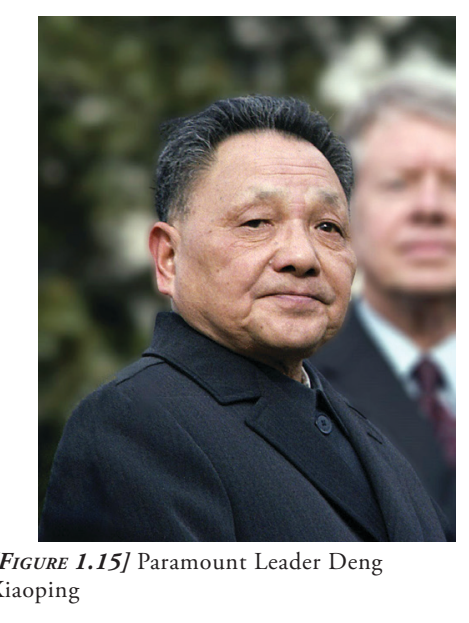
policy instituted in the 1950s and 1960s. By December of 1978 Deng Xiaoping [F[G.1.15] had permanently supplanted Mao as paramount leader of the CPC and the defacto leader of China. Deng advocated for educational reform, attributing the generation of undereducated citizens to be a direct result of the deterioration of education during the Cultural Revolution. ${ }^{1}$ In an effort to combat the detrimental programmes and policies of the previous government, Deng outlined a new policy emphasizing the goals of "the Four Modernizations:" modernization of agriculture, industry, science and technology, and defence. ${ }^{2}$ This movement caused a flood of foreign investors and manufactures to set up in major cities and aided in the rapid industrial development of the country. This was the complete antithesis of Mao's vision for China, believing in self-sufficiency and internal solutions to the nation's problems. Deng, as well as his later successors, actively sought cooperation from the rest of the world and faced criticism for leading China 
down the path to becoming a capitalist state from a faction of the country still committed to Mao's ideals. ${ }^{3}$

Where communal living characterized domestic architecture of the 1950 s to the 1970 s, by the 1990 s the notion of private home ownership, an anathema under Mao, became a pillar of economic growth in China. In the late 1970s, Deng gradually began dismantling the collective communes and reassigning land to rural families. Farmers were once again able to buy and sell the rights to use their plots of land. No longer obligated to contribute to a collective commune, family farming within the country was restored, however not the familial mode of social organization. The family unit, where quantity was once seen as a benefit to the family's overall success, has also been on the decline. The average household size of 5.4 in the 1910 s, was around 4.5 in the 1980 s and only 3 by the early $2000 s^{4}$. This decrease can be attributed to implementation of the "One-Child Policy," a program designed to regulate the number of children a family was allowed to have in response to the population boom that started in the $1950 \mathrm{~s}^{5}$. The government set targets for the total number of births allowed in each geographical region and these numbers were closely monitored through the Danwei. Unlike the Communes, the Danwei structure was not dismantled and instead continues to operate in a similar fashion, albeit with fewer restrictions as in the past. The Danwei control a dossier of each individual employee, regulating their daily lives. Young individuals require permission from their Danwei in order to marry or have a child, look for new employment, or travel and 
stay in a hotel. The government used the all encompassing control of the Danwei to effectively control the social program of the country.

As China's market economy was improving, much of the growth was experienced in the cities. With the collapse of migration control the 1980s, many travelled from the countryside for a chance to share in the country's new wealth. The rapid construction of communes and danwei infrastructure in the 1950s and 1960s left China facing a land shortage problem around major cities, with at least fifty percent of the previously agricultural land around these cities being taken over by urban expansion. ${ }^{6}$ This, along with people's desperation for new opportunities in the city resulted in poor living conditions for many migrant workers, with many often sharing a room with dozens of others, living dorm style, or in the shantytowns surrounding the urban core. As a result of this rapid urban growth, the housing built during this time typically ranged from twelve to fifteen stories high and almost never fell below five stories in order to compensate for the high influx of new residents. $^{7}$

Since the beginning of his reign, Mao had a very utilitarian way of approaching housing in China. He sought to employ architecture as an agent of the party through the implementation of a collectivized design approach. He striped away the traditional ties many had nurtured with their family home and abandoned the importance of "critical regionalism" in the design of his collective housing. Housing typologies continued to follow the same monotonous functionalist style 
introduced by the Soviets in the early 1950s, simple and dull. These buildings ranged from three to ten stories, and no matter the location, all following a similar type of regularity and symmetry. Following the death of Mao, this type housing construction continued to emerge throughout China's economic reform of the late in 1970s and 1980s.

These reforms have had continuing impacts on interpersonal relationships and family dynamics still present today; most notably, the separation of the family. This separation, which began with the Maoist policies of the previous decades, was exacerbated by one of two general conditions. One is that of the rural migrant family. In search of work parents are forced to leave their children behind in the care of either an older sibling or else other family members. Over worked and underpaid, they would often live in cramped, subpar apartments in order to build up a savings to finance their children's education. Typically these families are reunited just once a year to celebrate the New Year. The second condition contributing to the continued division of the family unit in the 1980s was the widespread demolition of family homes in the name of rejuvenation and increased population density [FIG. 1.16]. The increased flow of residents into urban centres led to major land shortages resulting in the government evicting residents and demolishing homes in order to make way for new development. The households which were most affected by this policy were typically low income families or individuals living in the older, ill-maintained structures. The government would sometimes relocate the existing families, usually displacing 
them into cheaply built apartments away from their work, school, friends, and family. More often, however, relocation was not addressed, evictions were unexplained, and fear and force was used to execute these changes. The government continues to promote this practice today as necessary in the economic growth of the nation, claiming that "land re-development, at whatever cost — whether for new roads, factories or residential complexes — is seen as the most direct path to visible results." [FIG.1.17]

Under the current government, China follows a similar capitalist-socialism format as their post-Mao predecessors, with current President $\mathrm{Xi}$ Jinping [FIG.1.18] serving as the paramount leader of the party. Operating in a state of apparent stability, the overall economy of China has been growing at an unprecedented rate since 1978. Architecturally, China has been at a state of uncertainty. Since the rejection of traditional styles under Mao, China has been on a path of discovery for what "Chinese Architecture" means. In recent years, some argue that the country became a stage on which western 'starchitects' came to push the boundaries of their creativity. With xenocentric buildings like the OMA's CCTV Headquarters [FIG.1.19] and Zaha Hadid's Guangzhou Opera House [FIG.1.20] shaping the skylines of cities across the country, China has become an architect's playground with very little rules or restrictions. In combination with these gigantic civic architectures, large amounts of residential housing have also been erected across all major cities. These cities are riddled homogeneous, soaring residences, where often a whole neighbourhood would be filled

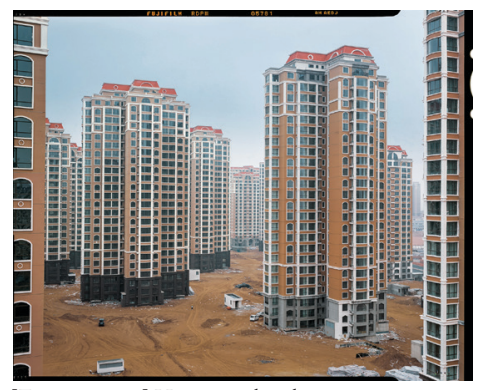

[FIGURE 1.17] Housing development in Ordos, Inner Mongolia. Often described as "ghost city", indicative of China's economy slowing down in the 2010 s

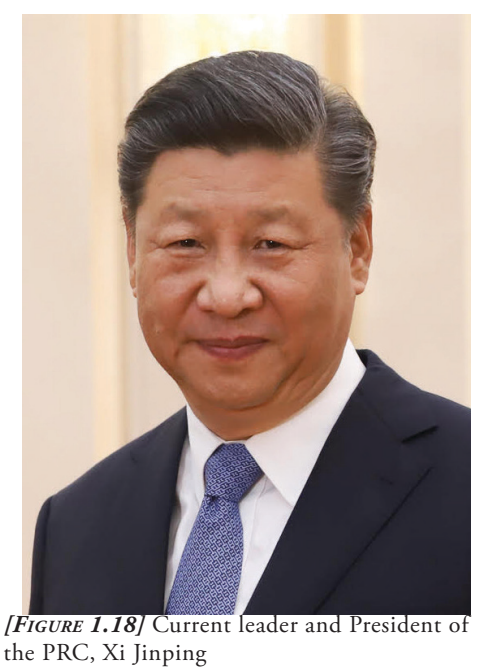
the PRC, Xi Jinping

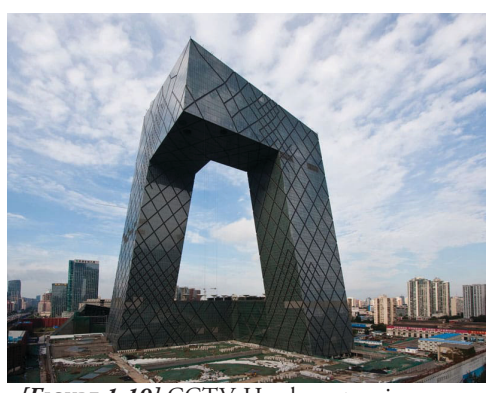

[FIGURE 1.19] CCTV Headquarters in Beijing, designed by OMA 2012

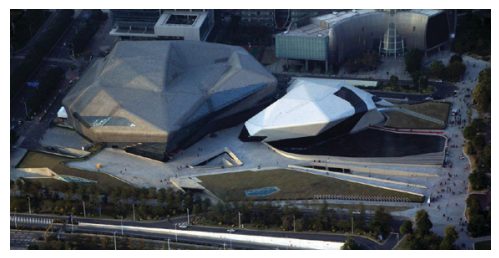

[FIGURE 1.20] Guangzhou Opera House by Zaha Hadid Architects, 2010 
with the same exact building. The combined effects of a lack of diversity in design and exuberant exercise of architectural power have created a confused presentation of what "Chinese Architecture" is in the modern world.

The growth of the economy can, in part, be credited to the change in political attitude the PRC have adopted since the reform. This political change has had resulting affects on the structure of life in China. The social dynamics of the family have since evolved, with the end of the collectivist structure returning a sense of individual freedom to the citizens. Large family structures no longer exist like they did in the early twentieth century, and the separation of family under Mao is no longer enforced. This new generation of family has become more self sufficient, no longer depending heavily, physically or financially, on other members. Emotionality, desires and personal freedom have become more important in China today and are often topics of discussion within the family. Many individuals are making choices in accordance with personal necessity and individual life aspirations, not necessarily sacrificing their interests for the sake of ensuring the patrilineal family line. In some ways this new outlook can also be detrimental to the structure of the family. As more members of the family move away or lose interest, the once close knit culture begins to fade.

China's economy continues to grow at an astounding rate, outpacing most western countries, including the United States. For the most part, architecture today has continued on the same trajectory as that which was established in the late 
1980s and 1990s. Cities are consistently reaching new heights, both physically with the construction of new towers, each taller than the next, and economically with the continuing growth of global trade [FIG.1.21]. As quality of life in China is slowing improving, so does the cost of living. When China introduced the universal two-child policy in 2015, replacing the previous the policy and lifting the restriction on family's to only have one

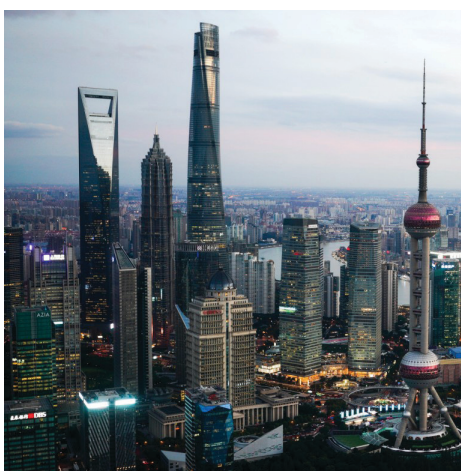
building in China, the Shanghai Tower, in the middle.

child, it was in response to the aging population, skewed gender ratio, and decline in the working age population. ${ }^{10}$ Today the number of births are slowing rising, but at a much lower rate than the government projected, many families are taking into account the socioeconomics of raising multiple children rather than adhering to the state imposed fertility policy. This setback represents an indirect act of resistance against the increasingly tenuous control of the government over the domestic lives of its citizens. This apparent loss of political power can be seen as an instigating factor to the central government's attempt to regain control, with the CPC announcing the removal of term limits for presidency and vice-presidency at the Chinese National People's Congress in March 2017¹. Under the 1982 Constitution, the introduction of a two term limit was in response to the destabilizing effects the party experienced under Mao and his Cultural Revolution. With this historic move Xi is now considered "the most powerful Chinese leader since Mao," ${ }^{12}$ signalling Xi's willingness to break from tradition and centralize power under him. However this sudden change in the constitution can signal a sense of instability in the PRC and the lack of regularity can be reinterpreted in future resistances. 


\section{Endnotes}

1 Ebrey, History of China, 333-334.

2 This new campaign is in juxtaposition to the Maoist campaign on the "Four Olds": old customs, old culture, old habits, and old ideas.

3 Ebrey, History of China, 357

$4 \quad$ Zeng Yi et al., "Changes in Family and Population Reproductions in China," in Changing Family Structure and Population Aging in China (Beijing: Peking University Press, 1990), pp. 58-81.

5 a. Modified version of this policy is still in place today, if both parents are only children the couple can have another child.

b. Throughout the 1950s and 1960s, the Chinese population grew by about 2 percent per year. By 2007, the rate of population growth had slowed to 0.7 percent per year.

David Howden and Yang Zhou, "Why Did China's Population Grow so Quickly? ," The Independent Review 20, no. 2 (2015): pp. 227-248, 228.

6 Ebrey, History of China, 343-344

7 Anne-Marie Broudehoux (McGill University, 1994).

8 The term Critical Regionalism was introduced in 1981 by Alexander Tzonis and Liane Lefaivre in their article "The Grid and the Pathway" and in 1983 Kenneth Frampton authored an article on the same subject. According to the definition of these authors, Critical Regionalism emphasizes the importance of "placeness" by considering contextual elements like scenery, historical references, and light, without falling into imitation and traditionalism.

Boltz-Bornstein, Thorsten. "Wang Shu and the Possibilities of Architectural Regionalism in China.” Nordic Journal of Architectural Research, 2009, 4-17

9 a. 1.5 million people were displaced from their homes in the run-up to the Olympics in Beijing between 2000 and 2008.

b. In the countryside alone, a 2011 study by the Landesa Rural Development Institute, found that 43.1 percent of villages had experienced land expropriation since the late 1990 s and that the number of cases each year have risen steadily since 2007.

"Amnesty International," Amnesty International (Peter Benenson House, 2012), https://www.amnesty.org/download/Documents/20000/asa170012012en.pdf, 15.

10 Zeng, Yi, and Therese Hesketh. "The Effects of China's Universal Two-Child Policy." Lancet (London, England). U.S. National Library of Medicine, October 15, 2016. https:/www.ncbi.nlm.nih.gov/pmc/articles/PMC5944611/.

11 Mary Gallagher, "Does a Stronger Xi Mean a Weaker Chinese Communist Party?, " The New York Times (The New York Times, March 2, 2018), https://www.nytimes. com/2018/03/02/opinion/xi-jinping-china.html.

12 Charlie Campbell, "China: Why Xi Jinping May Have to Rule for Life," Time (Time, March 12, 2018), https://time.com/5195211/china-xi-jinping-presidential-termlimits-npcl. 


\section{[IV] Architectural Resistance and the Government's Response}

The concept of architectural resistance has been prevalent in China since the 1930s and 1940s. Following the

fall of the Dynastic era in which architectural ventures were limited to temples, grand spaces, and gardens, modernism and westerners introduced for the first time, a grandiosity in architecture for lay people, albeit wealthy laypeople [FIG.1.22]. Early modernism in Shanghai and Nanjing allowed architecture

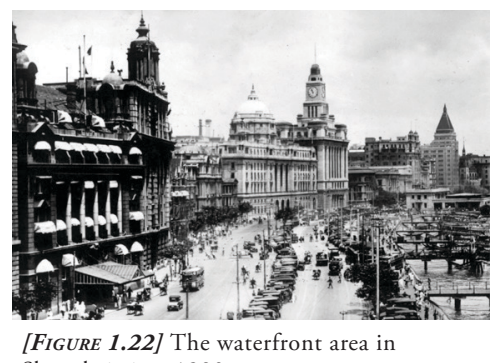
to be individualistic, experimental, and an autonomous discipline. ${ }^{1}$ This can be seen as an early act of architectural resistance against the prevailing architectural dogma which had been imposed under Dynastic rule for centuries. As Mao sought to "nationalize"2 the profession in the mid-1950s, he prohibited the existence of independent private practices. Many architects who rejected the idea of a nationalized architecture, took their practice underground and continued to exist for a period of one to two years after the government's prohibition. ${ }^{3}$ In many ways Mao's policy is a continuation of the architectural control imposed during the Dynastic era. For Centuries, the government had regulated the implementation of architecture throughout China, giving little to no agency to the architects.

In the 1980s the profession of architecture was able to revive its exploratory nature of the 1930s and 1940s with the relaxation of government control ${ }^{4}$. Initially, this new wave of "experimental architecture" offered architects grounds for 
formal experimentation while disregarding any socio-political commitments of the profession. The Split House by Yung Ho Chang [FIG.1.23-1.24] was a reinterpretation of the traditional Chinese courtyard dwelling, parallelled by his experimental utilization of traditional building materials like earth $(t u)$ and $\operatorname{wood}(m u)$. The potential modularity of the design offered a variety of amorphous courtyards and brought forth futuristic ideals on a traditional form. ${ }^{6}$ This was part of a larger project called the Commune by the Great Wall; a private development of twelve villas, designed by different emerging architects in Asia at the time. In contrast to the prevailing policies and programmes of the government which saw housing development as a practical and uniformed concept, this project

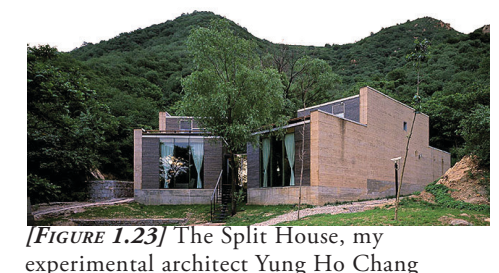
experimental architect Yung Ho Chang

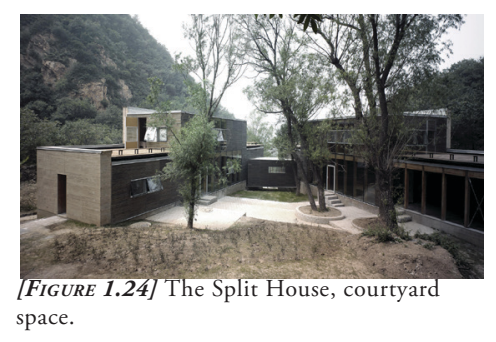
attempted to showcase the possibilities of intersection between traditional housing construction and emerging contemporary technologies. However, the design was critiqued for existing in a vacuum of space, too specialized and detached, calling into question the socio-economic commitment of emerging architects. ${ }^{7}$ This disconnect between architect, citizen, and the existing socio-political climate can be seen in many of the new developments that have contributed to the rapid erasure of homes. Though many architects at the time were designing homes that resisted popular appropriation, were syntactical and relational to the narrative of local context, and took into consideration the spatial experience of the people living there, they failed to acknowledge the experience of the existing residents who were losing their homes as a result of their 
designs.

Simultaneously growing with experimental housing and mass urbanization, another eclectic form of architectural style was also emerging across the country. A trend of architectural mimicry began in the 1990s, once again opening a discourse on the importance of critical regionalism. Many famous feats of Western architecture were being reproduced in Chinese cities, ranging from monumental structures like the Eiffel Tower [FIG.1.25] and the Empire State Building, to replicas of European towns, like Thames town [FIG.1.26] and the Alpine village of Hallstatt. This reactionary response is in reference to the economic growth of China and steady expansion of consumer culture with an increase in disposable income among the middle class. With people beginning to boast their newly gained wealth, Western culture became synonymous with wealth. China's economically elite would dine in Western restaurants, shop in Western stores and navigate streets bearing Western names. While this phenomenon can bee seen as a reflection of China's obsession with the West, some have argued [FIGURE 1.26] Thames Town in the Songjiang district. Named after the River Thames in
London, it exemplifies many classic British architecture styles. that it is not intended for flattery, suggesting instead that "the ancient parallels for these copycat projects [are] not mere follies, but monumental assertions of China's global primacy." ${ }^{8}$ This assertion is strengthened by the many visitors which suggest that these reproductions are an indication of China's rise as a global power, exemplifying the capabilities of introducing the wonders of the world to its citizens without the hassle of international travel. 
As experimental architecture continues to evolve in China, there are attempts by architects to address the issues of urban density and the rehabilitation of degrading homes. Architect Wu Liangyong's Ju'er Hutong Courtyard House [FIG.1.27-1.28] is regarded as an exemplary model for rehabilitation of the courtyard home. Completed in 1992, this renewal built on top of the existing framework of a single story courtyard home and replaced it two or three story apartments. Wu was able to maintain the cultural aspects traditional to the architecture of a courtyard home while still modernizing the city. In more recent experimentations, the People's Architecture Office have been addressing the neglected state of local residents by executing the Plugin system [FIG.1.29]. Constructed with modular parts, allowing ease of assembly and disassembly, it is designed to exist inside, adjacent to, on top of or completely detached from the original structure. The Plugin system significantly improved the quality of life, living conditions and energy efficiency, while preserving the historic buildings. By maintaining the separation of old and new, the experiment creates an atypical aesthetic between traditional and contemporary. This method of upgrading the deteriorating urban conditions without have to destroy existing buildings or relocate local residents allows for mass customization to suit the needs of each individual client. ${ }^{9}$ This alternative way of upgrading was something the government officials had seemingly never thought of, but since its success officials have begun funding and supporting future developments of this system. Existing at the intersection

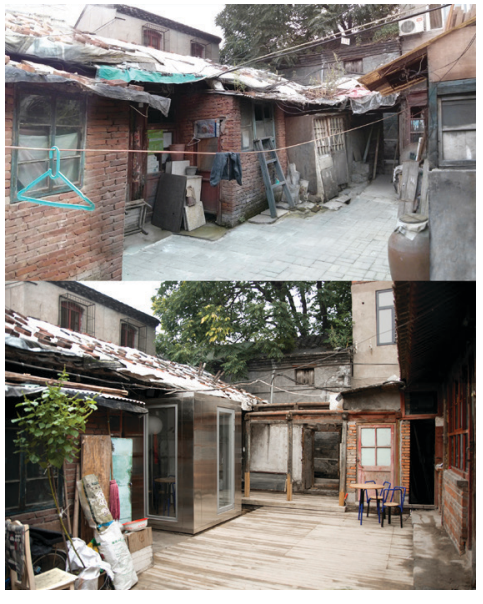

[FIGURE 1.29] Before and After the installation of the Plugin System, fully upgrading the unit without destroying the historic integrity of the courtyard. 
of complex social, political and cultural forces, the rise in the number of these projects across China have proven its viability within the wider context. ${ }^{10}$

The resistance of these built forms have elicited a response to from the CCP, influencing new changes from the central government. Having recently taken on more of an active role in development of architecture in China, on April 27 th, 2020, the country's housing ministry and the National Urban-Rural Development Commission released a statement outlining a "new era" for Chinese cities. The commission is calling for a ban on the obscenely tall skyscrapers, placing a 500 meter restriction on all new designs and an end to "copycat" architecture, signifying the changes in design culture of the country. The statement also warns against demolition of historical buildings, traditional architecture, or even old trees to make way for new developments, drawing significant contrasts to Mao's ideologies in the 1960s. Along with the emphasis on heritage preservation, the commission has also inserted a chief architect in each city to oversee all architectural developments therein. With this new system, China acknowledges the new generation of Chinese designers and their drive to create thought provoking architecture while still maintaining the urban fabric, ensuring buildings "embody the spirit" of their surroundings and "highlight Chinese characteristics." 11 


\section{Endnotes}

1 Jianfei Zhu, Architecture of Modern China: a Historical Critique (London: Routledge, 2009), 110.

2 In reference to the term Nationalization: the process of transforming privately owned assets into public assets by bringing them under the public ownership of a national government or state.

3 Bing Wang, "Structuring of the Architectural Profession in Modern China" (dissertation, 2004), 105.

$4 \quad$ Including art, fashion and filmmaking.

5 Where architects were rejecting the status quo and exploring the ontological aspects of architecture and the indigenous cultural tradition.

Guanghui Ding, "Experimental Architecture' in China," Journal of the Society of Architectural Historians 73, no. 1 (March 2014): pp. 28-37, https://doi.org/10.1525/ jsah.2014.73.1.28.

6 Guanghui Ding, Constructing a Place of Critical Architecture in China: Intermediate Criticality in the Journal Time + Architecture (New York, NY: Ashgate Publishing, 2015), 115.

7 Architect and Intellectual, Li Juchuan in an article in Time+Architecture 2002, translation found in Constructing a Place of Critical Architecture in China:

Intermediate Criticality in the Journal Time + Architecture , 117

8 Jack Carlson, “China’s Copycat Cities,” Foreign Policy, November 29, 2012, https:// foreignpolicy.com/2012/11/29/chinas-copycat-cities/.

9 Andong Lu and Pingping Dou, China Homegrown: Chinese Experimental Architecture Reborn (Oxford: John Wiley \& Sons, 2018), 50

10 Lu and Dou, China Homegrown: Chinese Experimental Architecture Reborn, 47-51

11 Matt Hickman, "China to Crack down on Copycat Architecture," The Architect's Newspaper, May 12, 2020, https:/www.archpaper.com/2020/05/china-to-crackdown-on-copycat-architecture/. 
PT. 2

METHODOLOGY 
There is a saying in Chinese that states "customs differ just three $l i$ away, regulations change a thousand $l i$ away." ${ }^{1}$ This idiom speaks to the country's vast multinational background, as local customs and geographical conditions have all been a factor in the different designs and development of housing typologies, changing over generations. From the Siheyuan in the North, the Tulou in the East, the Yekeyin in the South and the Aywang the West, China's traditional vernacular styles vary, but they all came to exemplify a standard form: a wood-frame construction surrounded by a court, by which to control and manipulate natural conditions. ${ }^{2}$ [FIG.2.1] In order to effectively consider the common spatial conditions of traditional vernacular homes in comparison to those of the communes and danwei of the Maoist era and post-Maoist residential buildings, it is necessary to establish a system of graphic representation which creates a common syntax across every time period. In this way the many varying physical manifestations and organizations of domestic architecture can be discussed in relation to each other through a shared graphic analysis. My methodology began by looking at the various documented drawings of vernacular Chinese homes by prominent architects Liang Sicheng, Lin Huiyin and Liu Zhiping, from their efforts to preserve and document much of Ancient China's architecture. ${ }^{3}$ Liu Zhiping is an especially important source for documentation of vernacular dwellings within the vast landscape, many of which are no longer standing. ${ }^{4}$ For this thesis I looked at six typologies of Chinese vernacular housing and analyzed their spatial forms, 

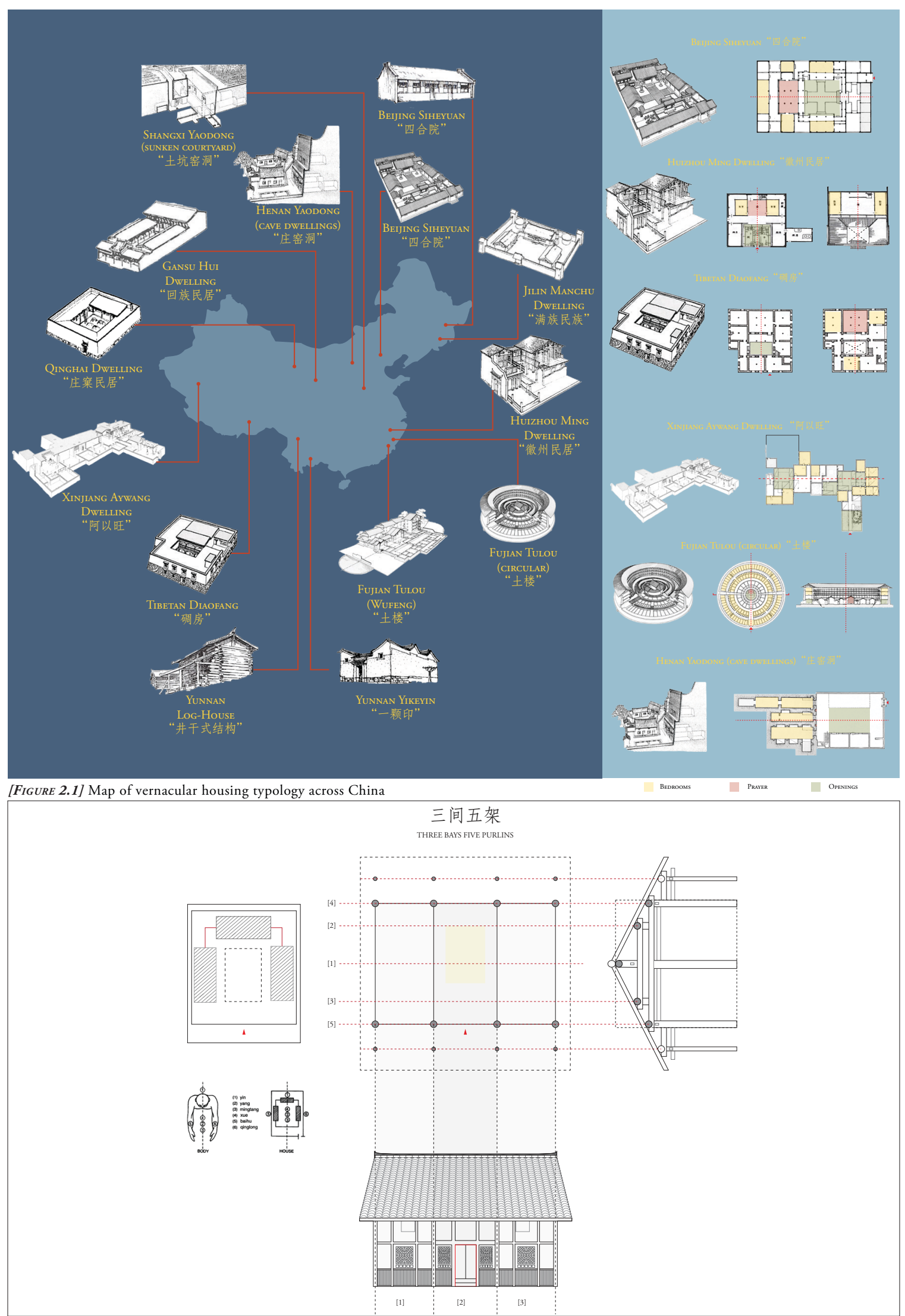

[FIGURE 2.2] The most basic of these forms is the lateral rectangular plan, typically south facing, it is a composed of 3 bays and 5 purlins 
the Beijing Siheyuan, the Huizhou Ming style dwelling, the Tibetan Diaofang, the Xinjiang Aywang, the Fujian Tulou, and the Henan Yaodong. [FIG.2.1]

In studying the designs of these homes, specific patterns in structure and spatial layouts become evident. An important factor in the construction of many Chinese vernacular dwellings is the implementation of bilateral symmetry, this can be clearly exemplified in the layouts of the Siheyuan, Ming style dwellings, and the Tulou, signifying balance, proportion, composition, order, unity, harmony and rhythm. Buildings or building complexes are designed to enclose the intimate spaces of the home from the public, typically surrounding an open space with its walls. These spaces, known as the courtyard (larger opening more commonly found in the north) and skywells (smaller openings commonly found in the south) are found in many different varieties, changing in response to local climatic conditions, sunlight, prevailing winds and air circulation. The projected hierarchy of traditional Chinese dwellings stem from the strict placement of spaces in relation to the property. Rooms or structures with doors facing the front are considered to be of more importance than the ones facing the sides or away from the front of the property. In the case of the circular Tulou the centre of the structure would be the space held with the highest esteem.

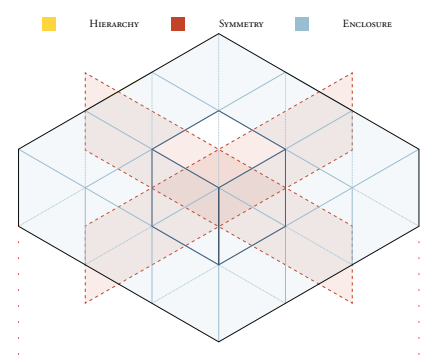

Utilizing the essential elements derived from these vernacular dwellings — symmetry, enclosure, and hierarchy — " I assembled a deliberate and selective system of representation. enclosure, symmetry, and hierarchy. 
The drawing system is represented in the form of a three by three grid, dematerializing the space and reconstructing it in a graphic way in order to find patterns within China's housing systems [FIG.2.3]. Simplifying the dwellings down to their most basic elements allows me to consider traditional vernacular homes in terms of shared ideologies of space rather than the varying physical implementations of those ideologies, further articulating the different categories in which politics and culture are expressed. In this way I am able to present a single traditional typology; a theoretical amalgam of the numerous vernacular iterations common to traditional Chinese domestic architecture.

The grid-system I devised to envisage a spatial typology of vernacular Chinese dwellings is also beneficial as a basis for comparison between domestic architecture of different time periods. My research into the domestic architecture of the Maoist and post-Maoist eras revealed that my grid-based system of graphic representation could equally be applied to the typologies of these eras. The Maoist domestic architecture of communes and danwei are characterized by spatial efficiency and modularity, resulting in a spatial organization that adheres to a grid-like layout. Similarly, post-Maoist domestic architecture, commonly multi-unit residential towers, are characterized by efficiency and repetition of form. This architecture of simple geometries allow the grid to be applied to domestic typologies across my three eras of interest and facilitates critical comparisons of specific typological spaces 
within those architectures across different time periods.

Domestic architecture is constituent of many various spaces which each serve unique functions of varying importance and significance. The evolution of the Chinese home in its entirety would pose an overwhelmingly complex study. For this reason it was prudent to limit the scope of this thesis. As such I made the decision to place a particular emphasis on the domestic spaces which have historically held the greatest [FIGURE 2.4] Diagrammatic drawing spatial
political and cultural significance within the home: spacespatterns found in Chinese vernacular dwellings. of prayer and reflection, spaces of dining, and the bedroom [FIG.2.4]. Spaces of prayer and reflection, typically the Main Hall, have historically been the "nucleus of the house and a symbol of its power and continuity" ${ }^{5}$ The Main Hall is where the family would come together in prayer and celebration and veneration of their ancestors. Spaces of dining, traditionally the baxian ${ }^{6}$ table around which the family would join each other for meals, "express familial unity and hospitality." And the bedroom was traditionally a multi-purpose space, serving as much more than a room in which to sleep. "It was here that women relaxed alone, kept busy with chores, visited with other women, or played and studied with children." who customarily had their own private bedroom, also "might rest, study, eat, and entertain on their couch beds," though they would not work from the home. Given their quotidian significance, these spaces are commonly those in which political and cultural change are typically implemented, reified, and reinforced or else, in the case of resistance, where political and 
cultural change is born. The importance of these spaces can be better understood in contrast to service spaces like kitchens, bathrooms, and corridors which play a more supportive role in the function of the home.

Endnotes

1 Based off of Chinese idiom 离家三里远, 别是一乡风 Wang Qijun, Vernacular Dwellings: Ancient Chinese Architecture (New York, NY: Springer, 2000), 125.

2 Wang, Vernacular Dwellings, 123

3 Liang Sicheng (recognized as the "Father of Modern Chinese Architecture" by Princeton University) with Lin Huiyin spent twelves years hunting and documenting ancient Chinese architecture through six architectural periods. Organized and published ten years after his death as A Pictorial History of Chinese Architecture: a Study of the Development of Its Structural System and the Evolution of Its Types.

4 Liu Zhiping, A Brief History of Chinese Residential Architecture (City, Residence, Garden) / Zhongguo Ju Zhu Jian Zhu Jian Shi: Cheng Shi, Zhu Zhai, Yuan Lin (Beijing, BJ: China Construction Industry Press / Zhongguo jian zhu gong ye chu ban she, 1990).

$5 \quad$ Knapp, Chinese Houses, 72.

6 The Baxian table, also known as the eight immortals table, it can used anywhere in the house. It represents a figurative expression of happiness accompanying the sharing of food.

7 Bettye S. Walsh and Howard Giskin, An Introduction to Chinese Culture Through the Family (Albany: State University of New York Press, 2001), 192.

8 Ronald G. Knapp, China's Living Houses: Folk Beliefs, Symbols, and Household Ornamentation (Honolulu: University of Hawai'i Press, 1999), 19.

$9 \quad$ Knapp, China's Living Houses, 19. 
A Catalogue of Space Within the Home 


\section{[I] Place of Prayer and Reflection}

北

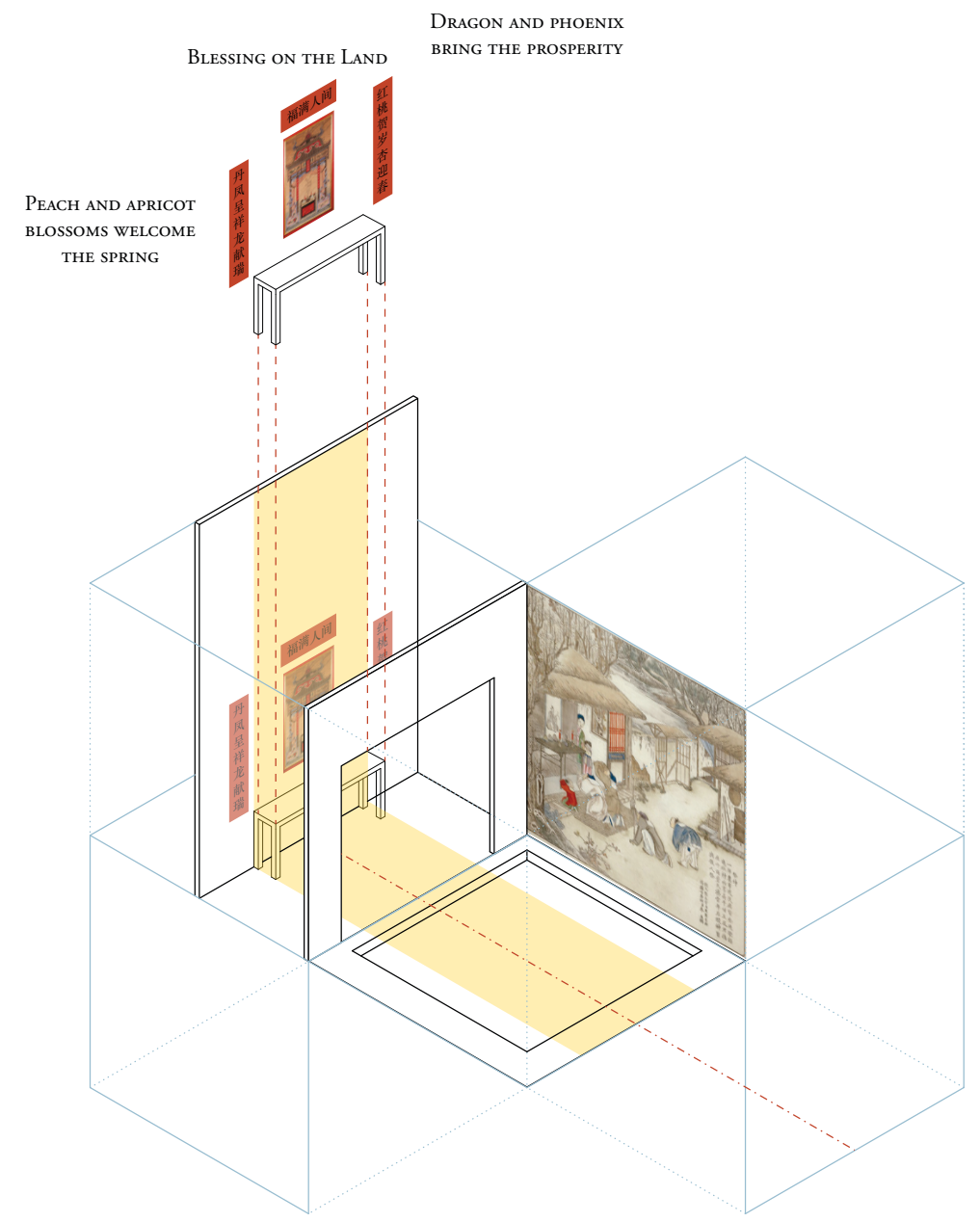

西

The Main Hall

[FIGURE 3.1] A graphic axonometric representation depicting the space of prayer during the Dynastic Period. The wash of colour is representative of spiritual or a hierarchical presence. 
Domestic space in traditional Chinese houses was extremely hierarchical. This characterization follows the cultural and social structures based on the Confucius principles. The most significant space in the spatial hierarchy of the house was the altar or praying space. The practice of prayer was commonly exercised in ancient China, no matter the financial situation or social position of the family, there was always a place for prayer and reflection in the home. It's prominence and importance was conveyed in many ways related to the architecture of the home. The altar was usually housed in what was referred to as the Main Hall of the house, or in a separate structure on the property known as the Ancestral Hall. The layout of a courtyard house is in accordance to the five Chinese cardinal directions, east (dong), south(nan), west $(x i), \operatorname{north}($ bei $)$, and centre(zhong). The most prominent directions being north and south: south being where the most sun is and therefore offering the brightest most fruitful land and north serving as the dichotomous concept to the south, the yin to its yang. Main Halls were typically constructed in the centre jian ${ }^{2}$ of the most northern section of the house, facing south. This space was most often the tallest points in the house, formally signifying its elevated importance in relation to the rest of the home. It was also the most ornately decorated and one of the most furnished room in the house, regardless of the family's economic status, adored with at least one pair of couplets offering harmonious juxtaposition on the wall along side the altar. Within the Main hall the ornate ancestral alter and ancestral tablets, personifying the familial 
ancestors and representing them in the present, commanding and further emphasizing the power and significance of this space. These traditional practices typically stemmed from Confucius principles, and was at the heart of Chinese society before the implementation of Maoist ideals in the 1950s. Prayer in ancient China represented communication between the spiritual plains, from deities to local ancestors and deceased family members. Rituals of all kinds were performed here, including daily worships, weddings, funerals, and annual festivities. ${ }^{3}$ The ceremonial space was not only used for spiritual connections, at times the Main Hall was also used as an intimate social space, a place to entertain family or friends, a place to drink tea and discuss business, or a place to read and study. This space was at the core of the domestic family home.

\section{Endnotes}

1 The Chinese order of direction is starts at east, going clockwise to imitate the movement of the sun.

Chen, Qun Rene. "Cardinal Directions In Chinese Language: Their Cultural, Social And Symbolic Meanings." ETC: A Review of General Semantics 66, no. 2 (2009): 225-39

2 Jian is in reference to the separation of bays in Chinese construction.

3 Ronald G. Knapp, China's Living Houses: Folk Beliefs, Symbols, and Household Ornamentation (Honolulu: University of Hawaii Press, 1999), 111. 


\section{Place of Prayer and Reflection}

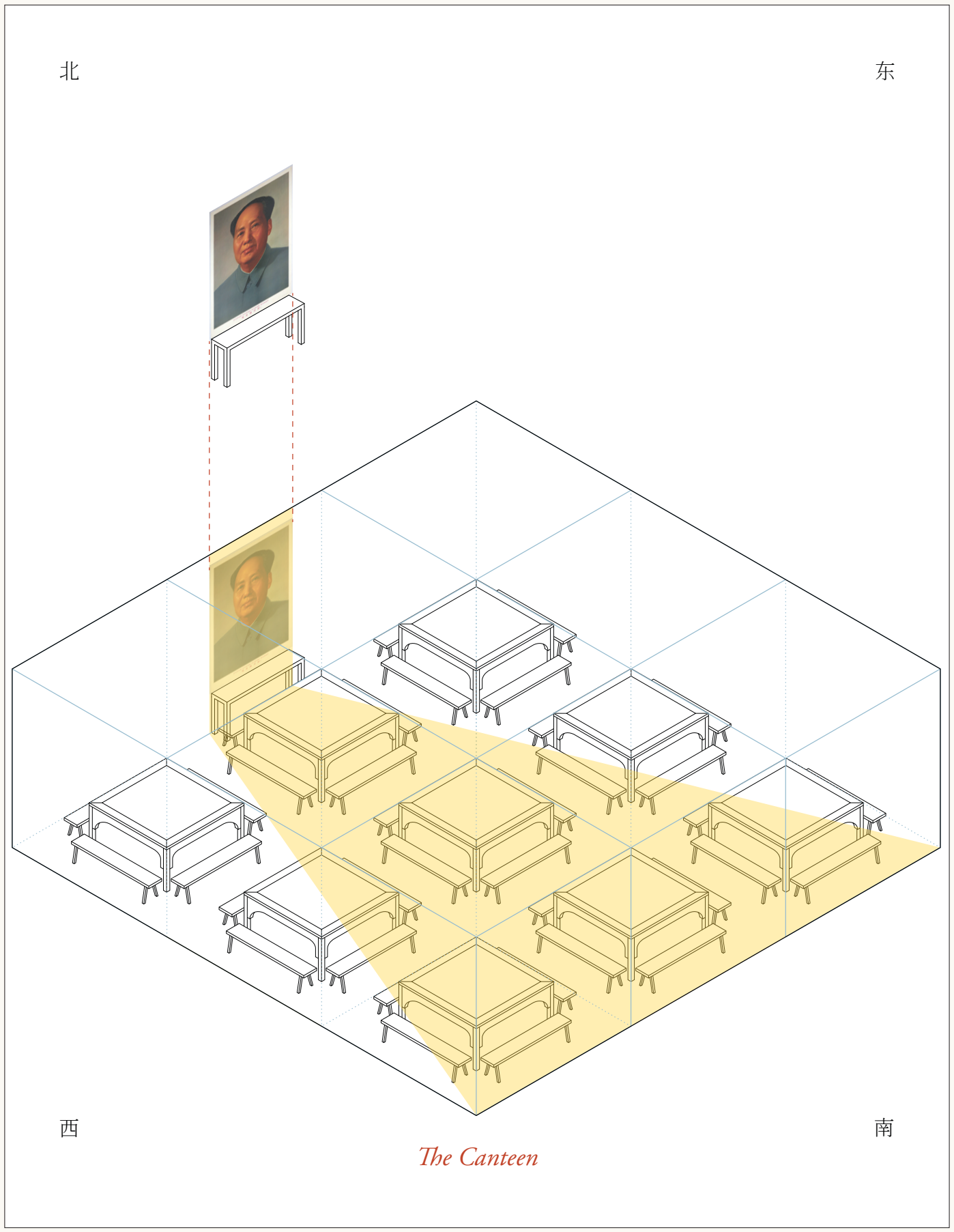

DURING

[FIGURE 3.2] A graphic axonometric representation depicting a space of political and personal reflection during the Maoist Era. The wash of colour is representative of the hierarchical presence of the political head of state 


\section{Place of Prayer and Reflection}

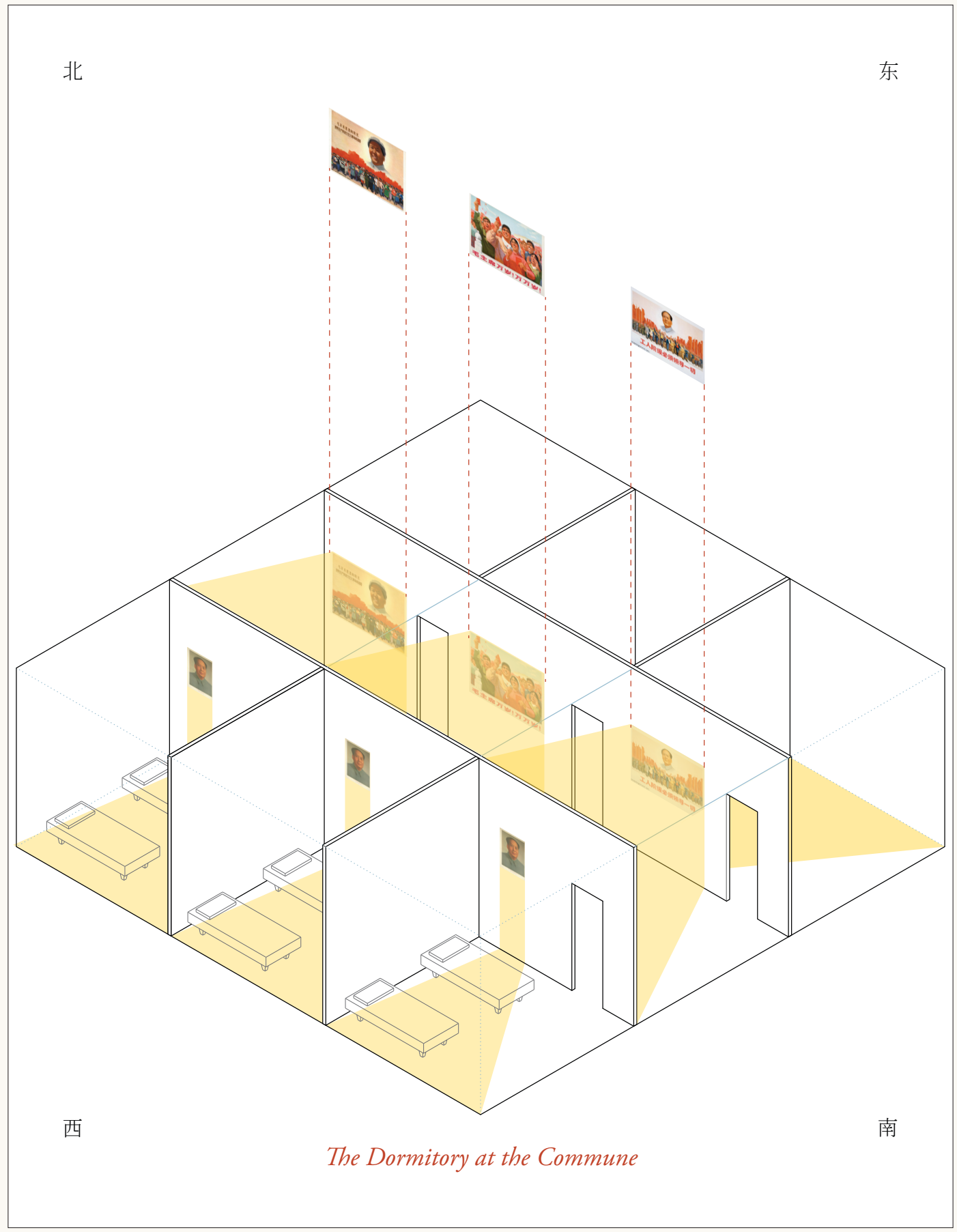

DURING

[FIGURE 3.3] A graphic axonometric representation which further emphasizes the overwhelming imposition of political dogma into daily life in the Commune. 
The hierarchical organization of domestic spaces radically changed in the 1950 s with the implementation of collective communes. The Communes were built without access to a Main Hall, abolishing traditional practices of ancestral veneration. The single spiritual space of familial congregation was replaced by a multitude of spaces throughout the commune, dedicated to images of Mao and iconography of his dogma. This new political veneration was encouraged in the communal canteen, schools, hallways, and even within the privacy of the bedroom. These new ritualistic activities were implemented through common interactions with Communist iconography, including standing in front Mao's picture and asking for daily instruction in the morning, and quietly confessing daily "sins" in the evening. ${ }^{1}$ These acts of "prayer" were under constant supervision by commune cadres and fellow commune members, turning prayer into an act of public theatre instead of private introspection. Mao's desire to install himself as the object of Chinese veneration resulted in a proliferation of these new public spaces of prayer in communes, removing the significance of spatial hierarchies that once informed spiritual space, and with it the social hierarchy of the domestic space at large.

\section{Endnotes}

1 Jiping Zuo, "Political Religion: The Case of the Cultural Revolution in China," Sociological Analysis 52, no. 1 (1991): pp. 99-110, https://doi.org/10.2307/3710718, 101. 


\section{Place of Prayer and Reflection}

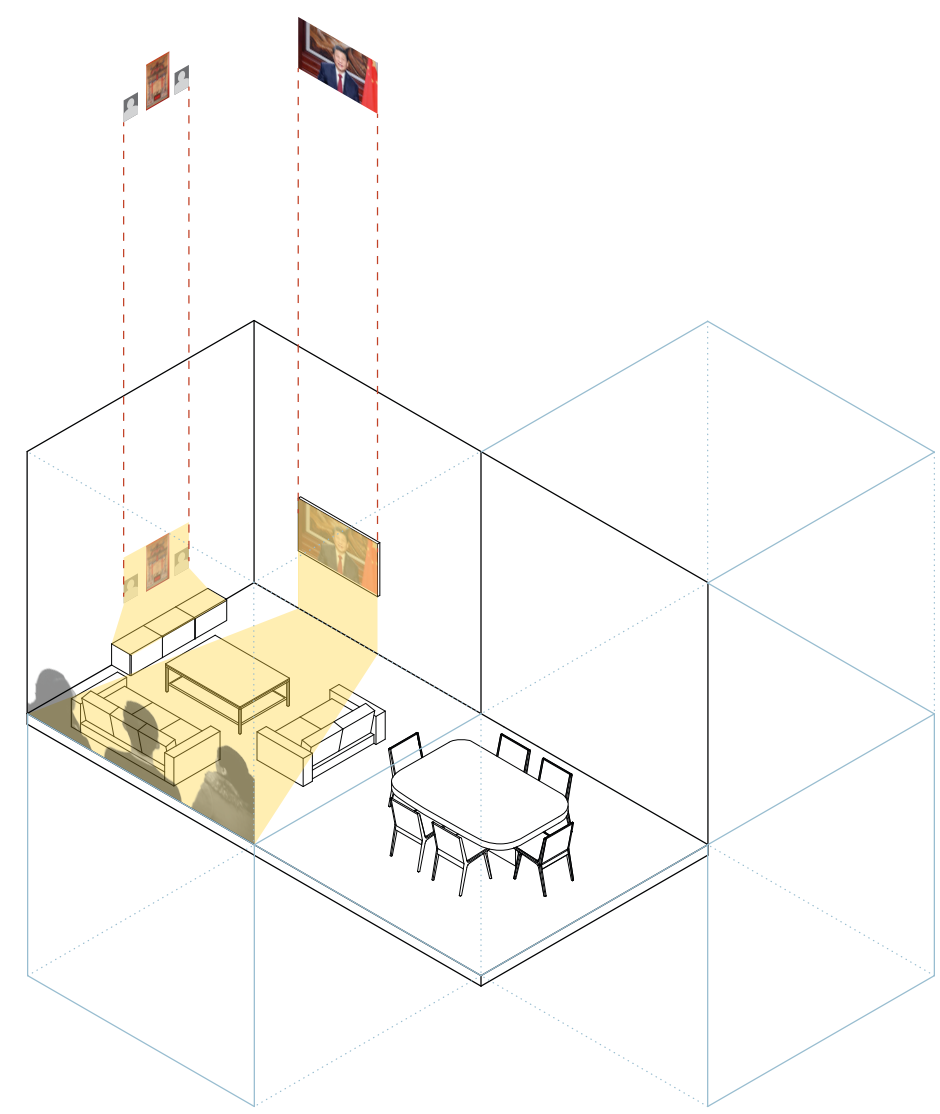

西

The Living and Dining Room

[FIGURE 3.4] A graphic axonometric representing the political and spiritual presence in the home today, the "political religion" taking up more space in the home than the ancestral shrine. 


\section{Place of Prayer and Reflection}

The Dining Room and Kitchen

[FIGURE 3.5] A graphic axonometric representing the transcendence of Mao from a political figure to a spiritual deity. Existing in parallel with ancestral veneration, many people today still uphold Maoist rituals and traditions. 
Spatial implications of prayer today are found differently within existing structures of domesticity. As a result of Maoist collectivism, control in spatial hierarchy once exemplified by the layout of domestic home have diminished, rather, hierarchy was constructed with images, iconography, and rituals performed publicly. Since entering the reform in the 1980s many have reestablished the practice of ancestral venerations, following the ethical doctrine of Confucianism, however with less gravitas in comparison to Dynastic times. New apartments are built without the establishment of space for prayer, devaluating the power it once held. Many times the space for prayer co-exists in a room engaged in various operations of day to day life, lacking the ancestral figures destroyed during the purge of the four-olds, instead photographs of deceased parents replace those symbolisms. The connotations associated with this alternative hierarchy exhibit a separation of familial power towards individual family members whist still maintaining the spiritual and cultural connections. Along side the traditional religion still exists the "political religion,"1 found mostly in the homes of older generations, posters and effigies of Mao or similar political figures would exist along side the ancestral ornamentations. These new spaces or prayer have removed the authority of ancestral veneration, however with the introduction of new medias the pressure of governmental veneration are still emphasized, uniformity of values and conformity to the party is subconsciously ingrained into the minds of the new generation, and the homogeneity of present domestic spaces seems to be aligned with this ideology. 


\section{Endnotes}

1 Jiping Zuo, "Political Religion: The Case of the Cultural Revolution in China," Sociological Analysis 52, no. 1 (1991): pp. 99-110, https://doi.org/10.2307/3710718. 


\section{Place of Prayer and Reflection}

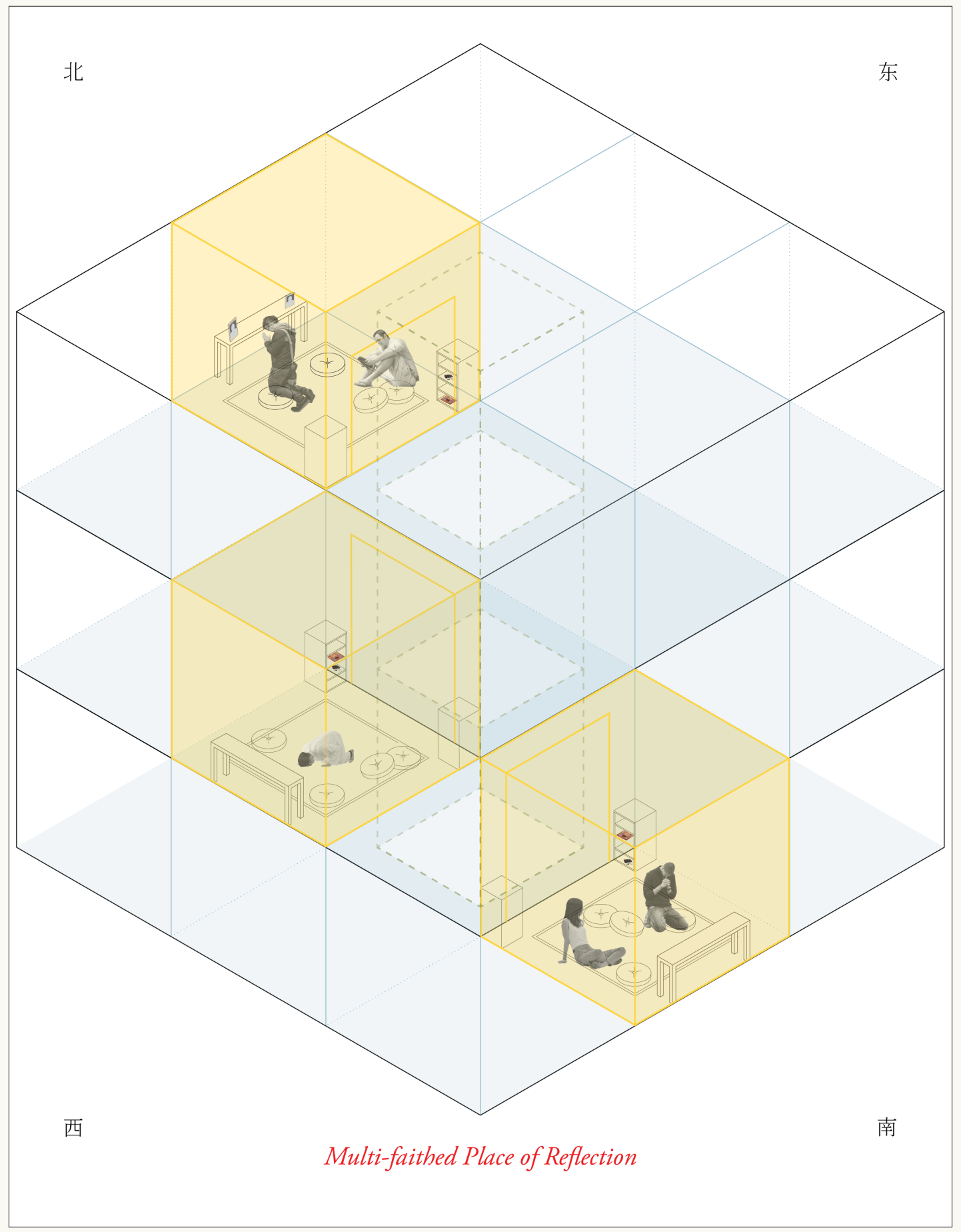

FUTURE

[FIGURE 3.6] A graphic axonometric representative of a multi-faith space in dense apartment buildings. Separating the space of prayer and reflection from inside the home, instead become an extension of the community. 


\section{Place of Prayer and Reflection}

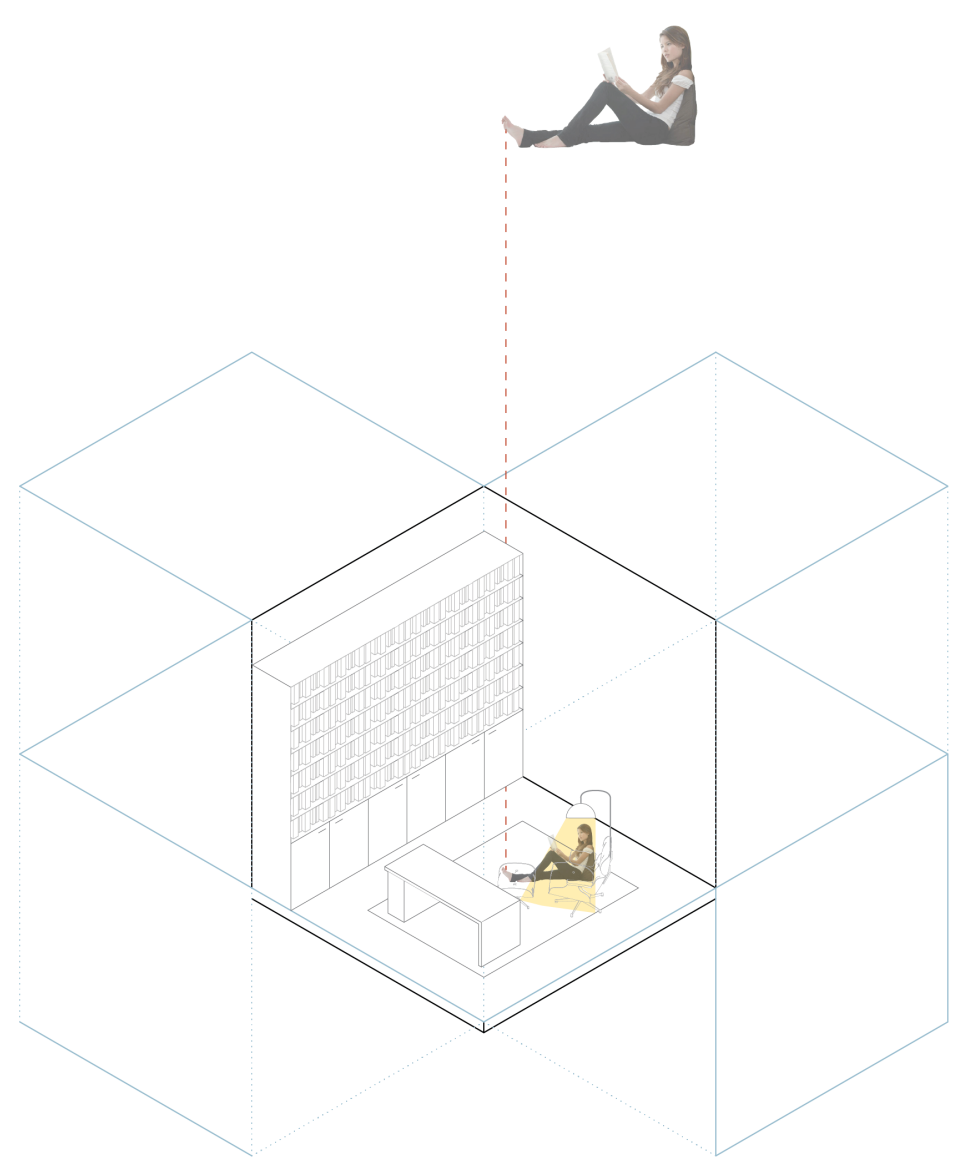

西

Place of Reflection

[FIGURE 3.7] A graphic axonometric representative of an alternative space of prayer and reflection in which a more fluid form of introspection can take place. This space facilitates various forms private reflection and meditation such as yoga, reading a book, or simply resting one's mind. 
My intention is for the speculative future of this space to be a reflection of the then contemporary political ideology, when China has entered into a democratic socialistic era, and individual freedoms are much more celebrated. This extends into a freedom of religion and with the continued exposure to cultures outside China, the religious demographics shift within. With continued densification of cities, the space of prayer evolves from an individual and separate practise into a shared social ritual between family, friends, and strangers. Communal spaces of gathering and reflection present on each floor of these apartment buildings offer a shared, multi-faith community space that would be open to various reflective practices.

Alternatively, as prayer, reflection, and spirituality gets redefined, individuals may opt for a more private, personal act of introspection apart from the strict ritualism of organized religion, seeking reflection in the pages of a book perhaps, or some other form of private meditation. In this way spaces of prayer and reflection are not limited to specially designated areas, nor to any physical space at all. Spaces of prayer and reflection become metaphysical, existing in an individual's mind, wherever they may physically be. 


\section{[II] Place of Dinning}

北

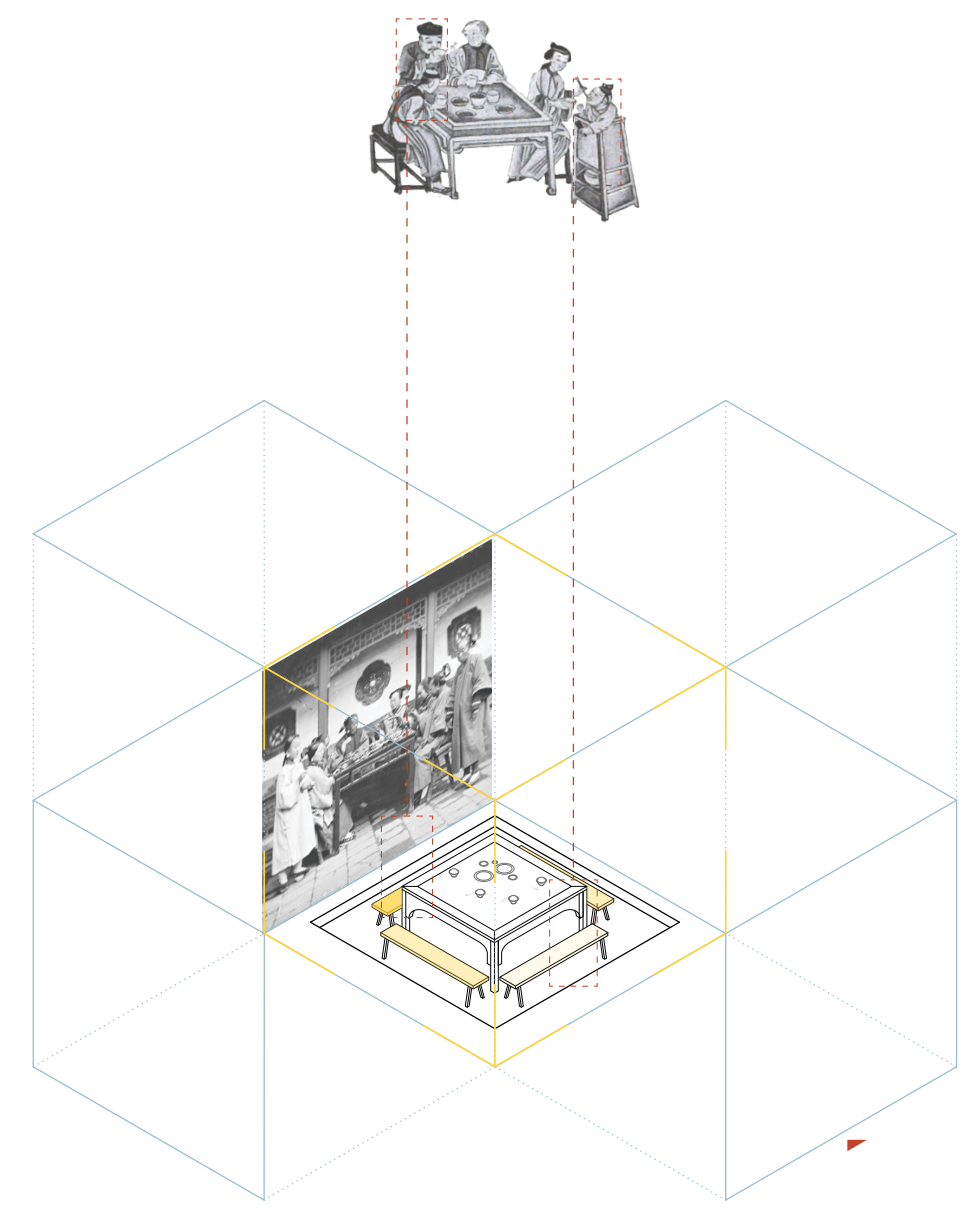

西

The Courtyard

[FIGURE 3.8] A graphic axonometric representing the act of dining as a hierarchical and familial experience. With the gradation of colour emphasizing the place of most importance. 
Oriented around the baxian ${ }^{1}$ table, the dining space "epitomized domestic life in a Chinese home." ${ }^{2}$ The ritualistic act of dinning was an intimate experience shared by members of the traditional family. Many times these meals would be served within the open courtyard surround by the home, and the table would be brought out from the Main Hall into the centre. The courtyard is an important element in the spatial layout of the home, further perpetuating the social hierarchies evident within the family. This central open space is representative of an individual's close connection to earth, a common spiritual belief that closeness to the earth corresponds to good health and fortune. "It is [within] these [open] spaces where there is nothing that the usefulness of the house depends. Therefore just as we take advantage of what is, we should recognize the usefulness of what is not. ${ }^{3}$ "This negative juxtaposition of the space in relation the rest of the house acknowledges the impactful space the courtyard creates in the design of the house. The orientation of the baxian table and those sitting around it in relation to the courtyard entrance carried its own hierarchical meaning relating as well to the hierarchy of the cardinal directions. Seats that faced south were seen as most ideal, and were often allocated the most senior member of the family. Subsequent seats are fanned out around it, as a result placing the youngest member facing the oldest. At times, in larger homes and families, there was a more strict separation between the sexes, women and girls would eat together while the men and boys ate together elsewhere. The act of dinning 
within the courtyard further cements the spatial importance of

the courtyard itself within the larger dynamics of the house and

family unit.

Endnotes

1 The Baxian table, also known as the eight immortals table, it can used anywhere in the house. It represents a figurative expression of happiness accompanying the sharing of food.

Ronald G. Knapp, Chinese Houses: the Architectural Heritage of a Nation (Singapore: Tuttle, 2018), 93.

2 Knapp, Chinese Houses, 76

3 Waley, 1958:155 The quote is from a fourth-century BCE work attributed to Laozi, anticipating the significance of voids. 


\section{Place of Dinning}

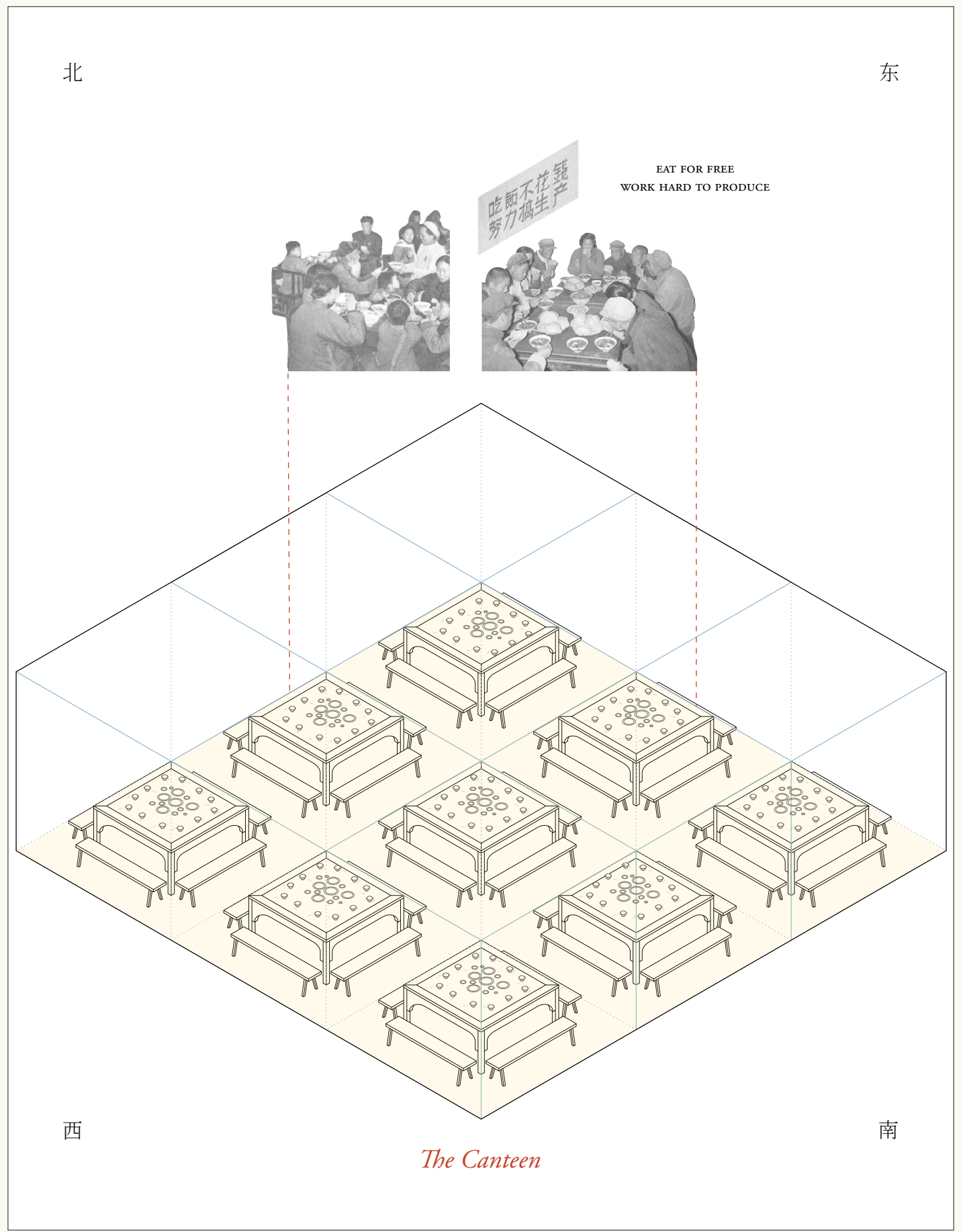

DURING

[FIGURE 3.9] A graphic axonometric representing the act of dinning stripped of its ritualistic and hierarchical implementations during the Maoist Era. 
With enforced communal dinning introduced in the Communes, the dinning experience lost its ceremonial and ritualistic character. The spatial organization of canteens disbanded any social hierarchies that were present in the traditional dinning etiquette of the past. The architectural design of the space, constructed in the same monotonous functionalist style as the rest of the commune infrastructure, evoked no spacial hierarchy. This large and impersonal space of the canteen facilitated dinning experiences for all commune members, this number ranged from 10,000 to 80,000 individuals, offering a drastic juxtaposition from the private intimacy once found in domestic dinning. ${ }^{1}$ Everyone ate in the same space, sharing the same food, with no individual held in higher regard than the rest. Similarly, there was no longer a separation of sex or sex-based hierarchies at the dinning table; men and women commonly ate side by side. There was no monetary cost associated with dinning at the canteen; meals were cooked internally in canteen kitchens and much of the food was contributed from commune farmlands and livestocks. The tables and chairs that furnished the canteen generally came from the private home of the families, or were made by the production team within the commune. This wilful disregard for the ancestral hierarchy was crucial in the separation of people from their traditional past.

\section{Endnotes}

1 Colombia University, "The Commune System (1950s)," Asia for Educators, accessed March 20, 2021, http://afe.easia.columbia.edu/special/china_1950_commune.htm. 


\section{Place of Dinning}

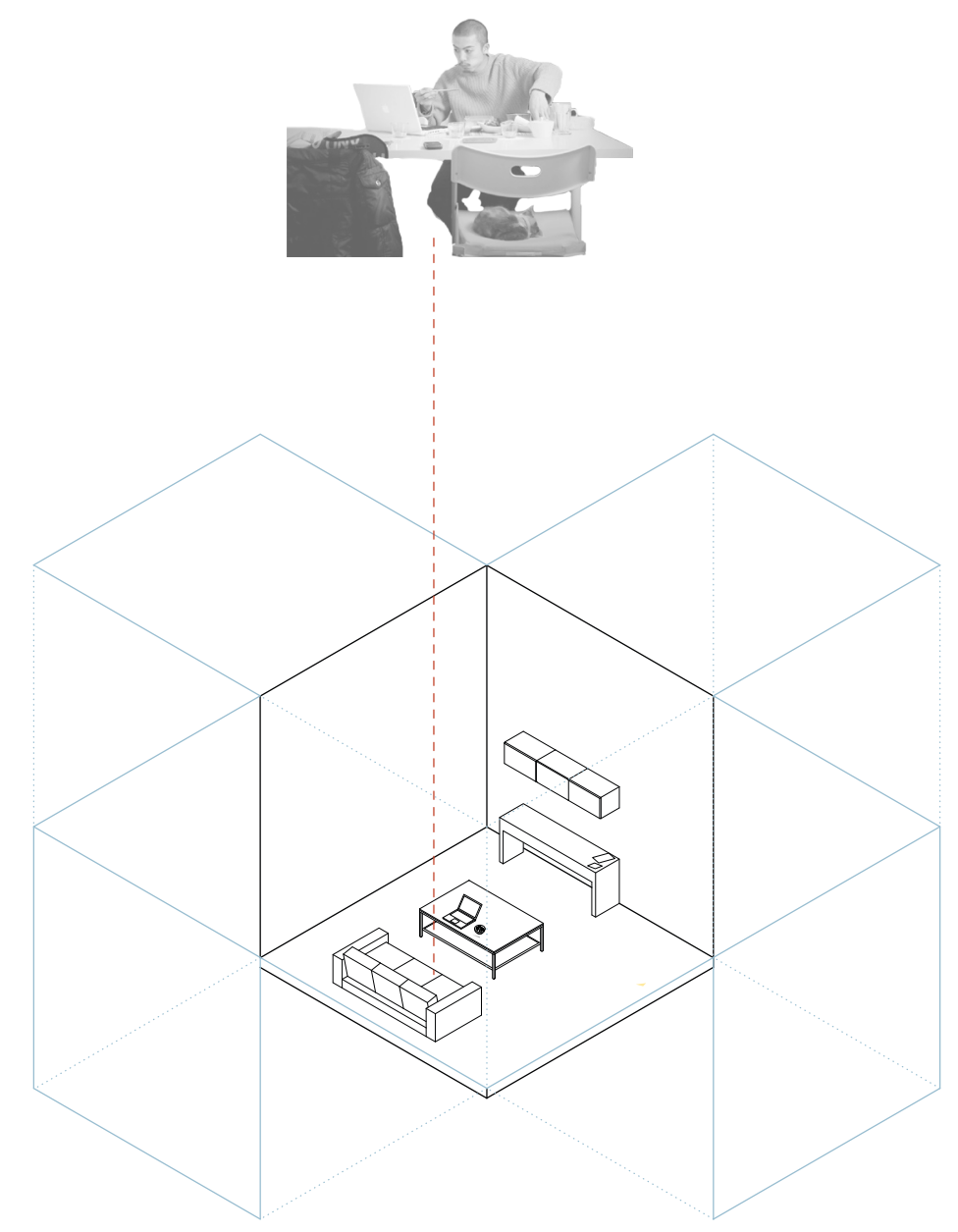

西

The Living and Dining Room

[FIGURE 3.10] A graphic axonometric of one dining experience today, physical interactions of dining have been replaced by the convenience of screens 


\section{Place of Dinning}

北

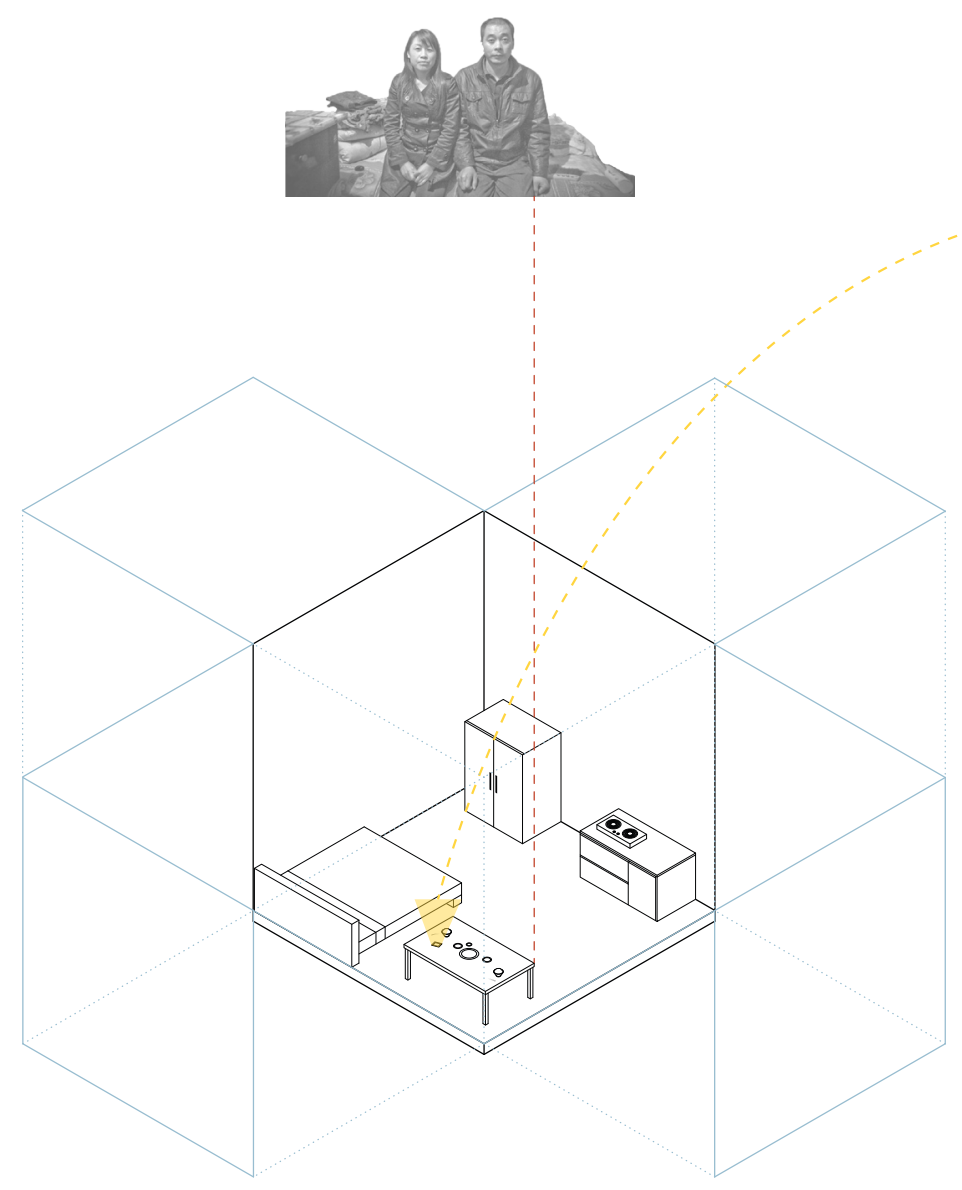

西

The Entire Apartment

[FIGURE 3.11] A graphic axonometric representing a problematic conditions of the family that exists today. The lack of jobs in many places have low-income parents migrating for work, separating from their children in order to give them a better life. 


\section{Place of Dinning}

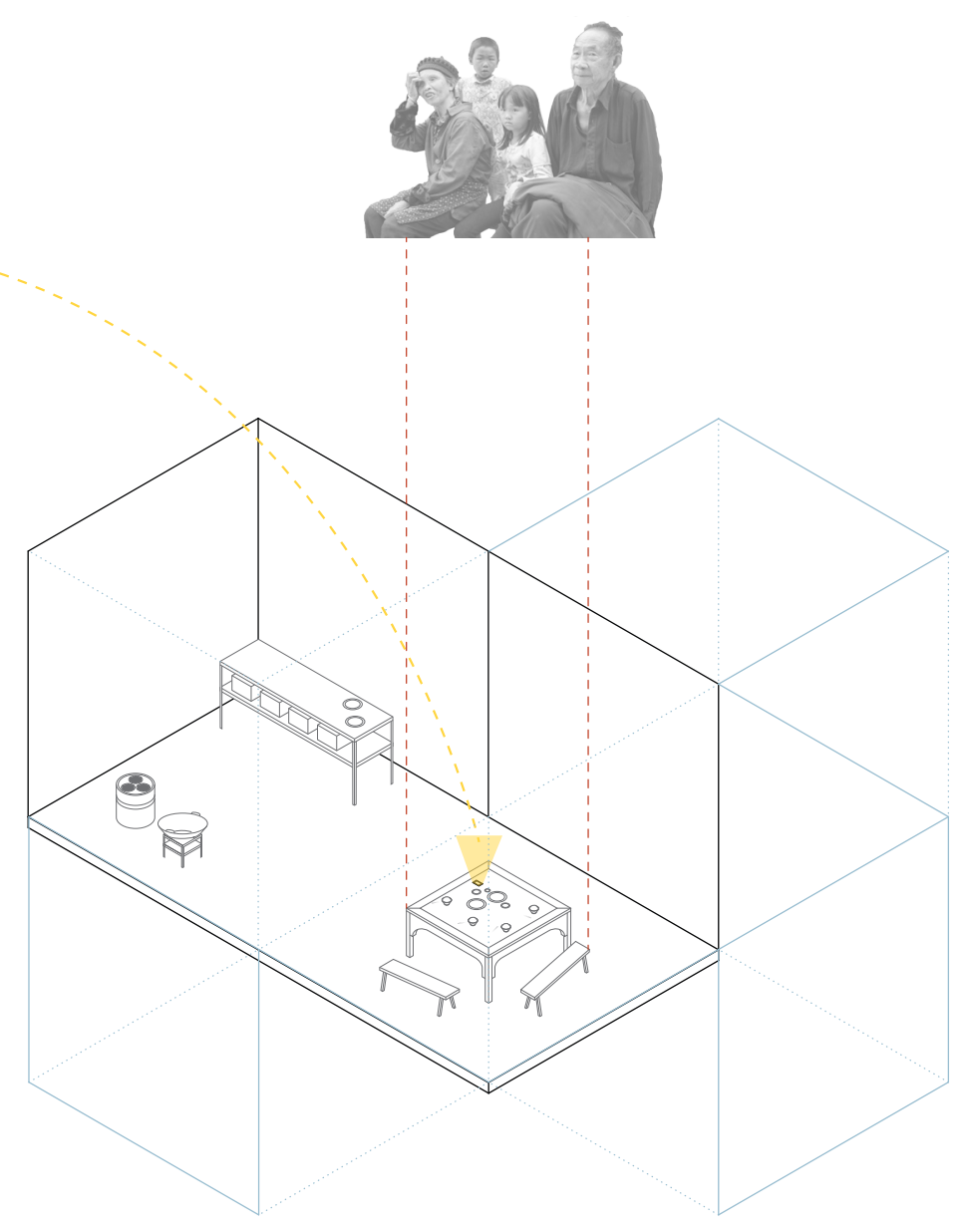

西

The Kitchen and Dining Room

[FIGURE 3.12] A graphic axonometric represents the other side of the previous familial scenarios. Raised by their relatives, the act of dining as a family only exists through the screens of the phone. 
The space of dinning today is characterized by comfort and convenience, the importance of the physical space and stringent hierarchy have become secondary. Removed from the strict traditions of the early twentieth century and the systematic control of the more recent past, the organization of the family home has become less structured. The dinning experience has once again become a private act, however the interpretations of how and where dinning can occur have changed. Utilization of digital technology and digital space have become more prevalent in todays dinning experiences, replacing the importance once associated with physical interactions. Separated through space and distance, the social act of dinning can now be experienced virtually in real time. Ritualistic dinning is still occurring, however generally under celebratory or festive pretences, mostly taking place within restaurants instead of in the domestic space. With the majority of the Chinese population now residing within dense urban areas, along the shrinking of family size, the act of dinning has become less family oriented. 


\section{Place of Dinning}

北

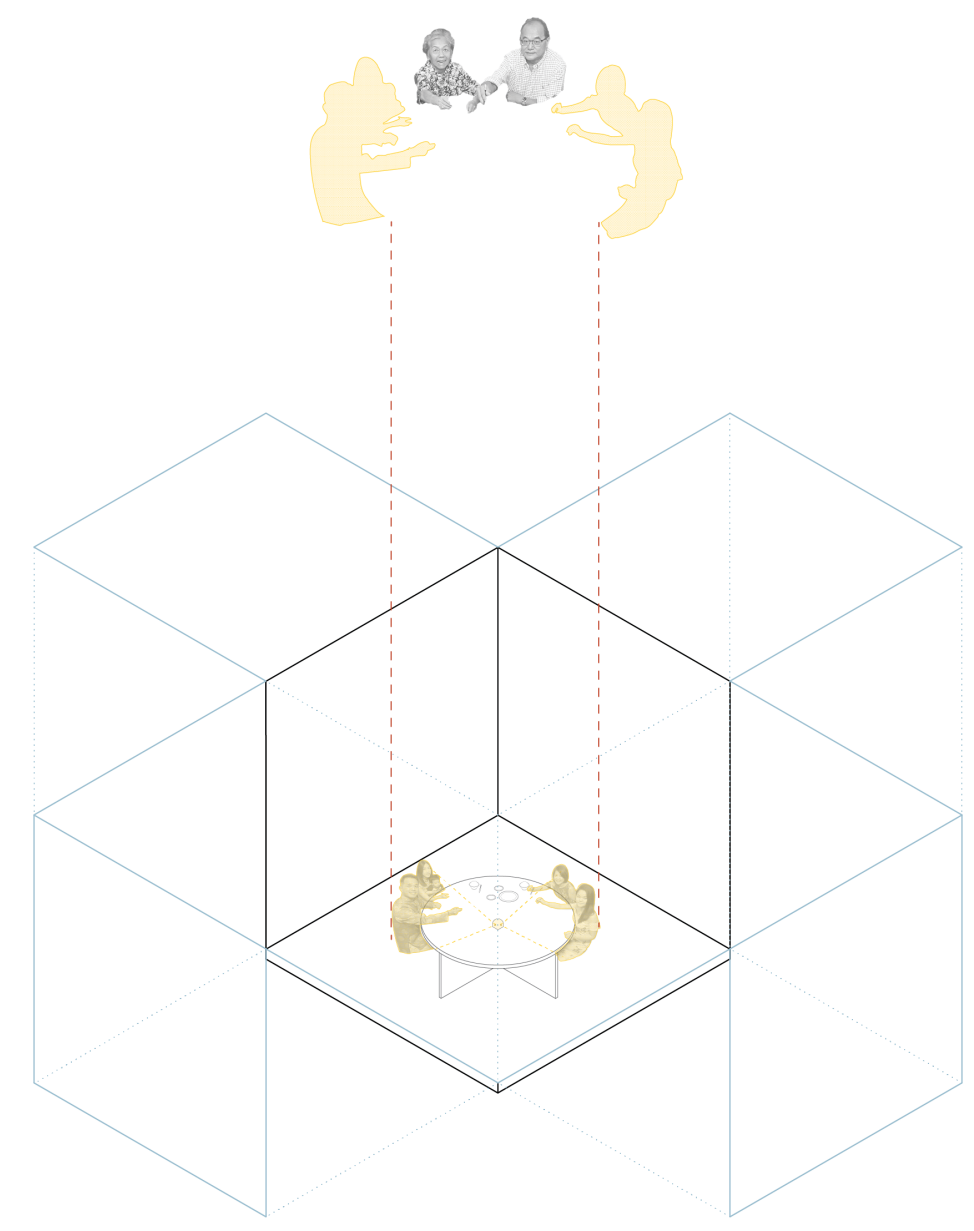

西

Virtual Dining Room

FUTURE

[FIGURE 3.13] A graphic axonometric represents the act of dinning in the future as a purely virtual event, utilizing the capabilities of holograms 


\section{Place of Dinning}

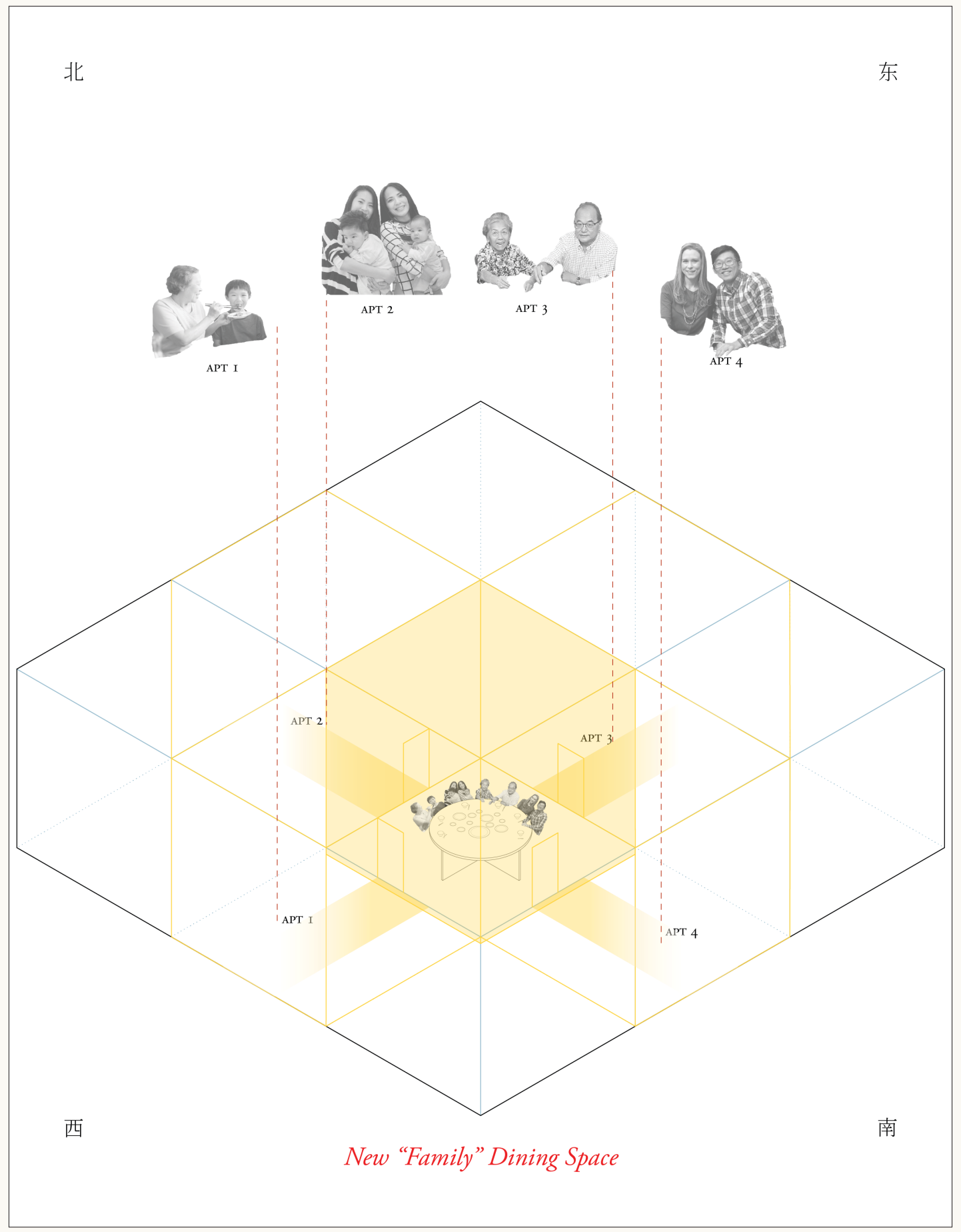

FUTURE

[FIGURE 3.14] This graphic axonometric represents the reactionary results of the scenerario in figure 3.12 , showing the concept of an adoptive community to substitute the lack of physical familial connections. 
As the population of China continues to grow and individual pursuits leads to many people living apart from their families, technology can serve to bridge the geographical gaps between people. My speculative interpretation of dining and gathering in the future is that it becomes a purely virtual act, advancing from just video calling to holograms and interactive $\mathrm{VR}$, bringing people together for celebrations and dinners. In such arrangements, the hierarchy of the dining space differs for each individual, placing themselves as the central figure around which the others are projected.

While the virtual can bring people together, it lacks a certain intimacy of physical interaction, causing individuals to seek this out in other ways. Individuals living in apartments can come together with others for meals and celebrations, redefining the traditional "family dining." Around these dining tables all are equal, however, as with the courtyards of old, the dining space itself becomes of greater hierarchical importance in the building as the space in which people gather and celebrate together. 


\section{[III] The Bedroom}

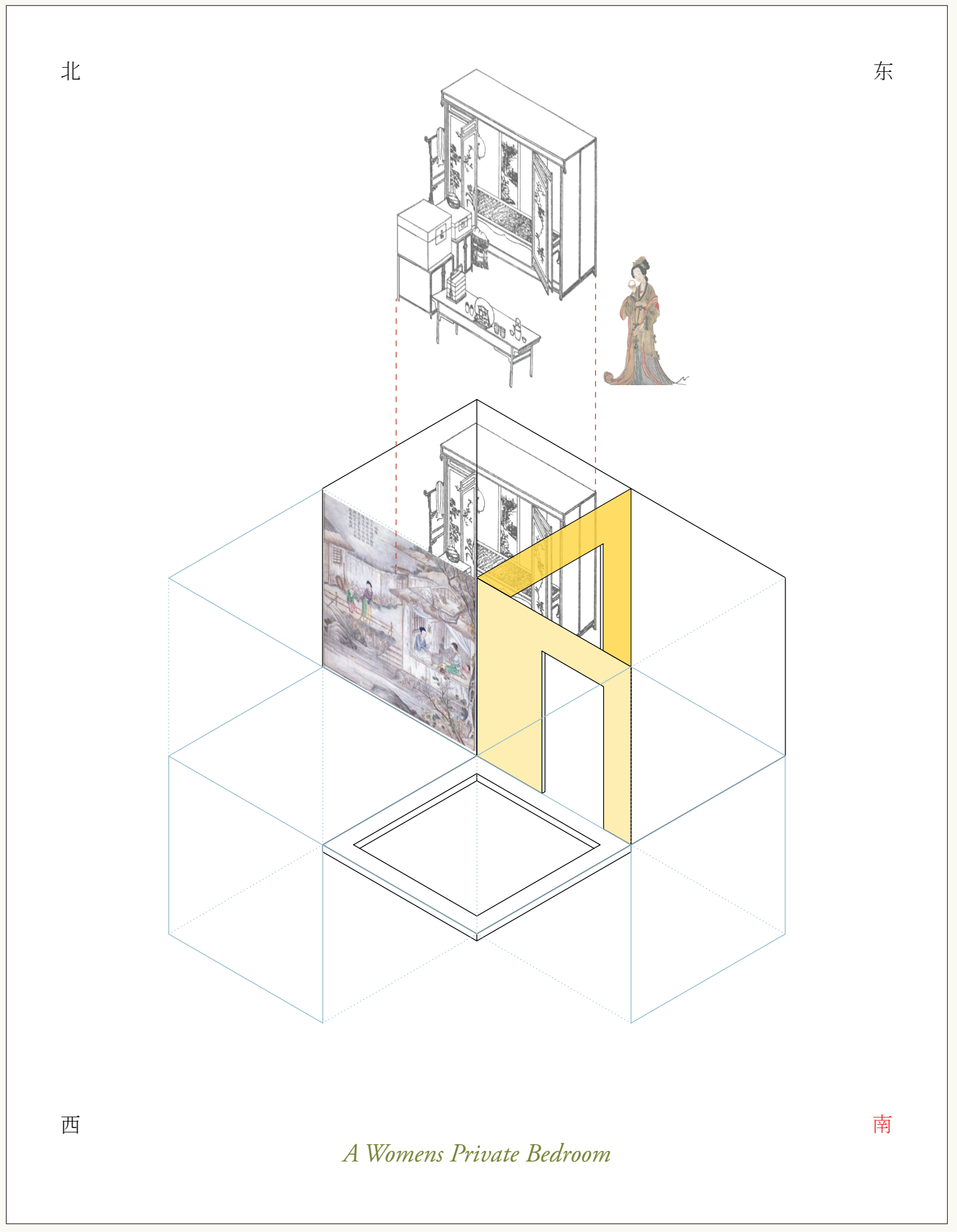

[FIGURE 3.15] A graphic axonometric showing the intimate space of a womans bedroom, a space of enforced privacy, not necessarily chosen. 
Within the intimate space of the bedroom, the prevailing dominance of social hierarchy is very much apparent. The separation of private space for men and women was strongly enforced, the women's bedroom were tucked further into the house or on the second floor, unseen by visitors. This segregation of spaces was carried out through the utilization of secondary passageways and doors around the house. The husband usually had his own bed but periodically visited his wife's bed, or rotated between the wives and concubines. This imbalance in power allowed the husband to come and go as they please, however the same authority was not given to the wife. In the Dynastic era, the living spaces were often shared with the working spaces, often requiring flexibility in the spacial uses of the dwellings. The bedroom was no exception, operating as more than just a place to sleep, it offered the space to address many household activities. Women in particular accomplished many of their daily chores not only inside the bedroom but on the bed itself, these range from food preparations, weaving and embroidery, as well as entertaining friends. ${ }^{1}$ Men, unexpected to work within the house, utilized their bedroom as a place of rest, study, and even eat. ${ }^{2}$ Further perpetuating the gendered inequalities of this time. The bed, generally large and imposing, often used as a form of social leverage as apart of the woman's dowery, further cemented the notion of women as property, first owned by her parents, then later by her husband.

\section{Endnotes}

1 Ronald G. Knapp, Chinese Houses: the Architectural Heritage of a Nation (Tuttle, 2005), 78.

2 Ronald G. Knapp, China's Living Houses: Folk Beliefs, Symbols, and Household Ornamentation (Honolulu: University of Hawaii Press, 1999), 19. 


\section{The Bedroom}

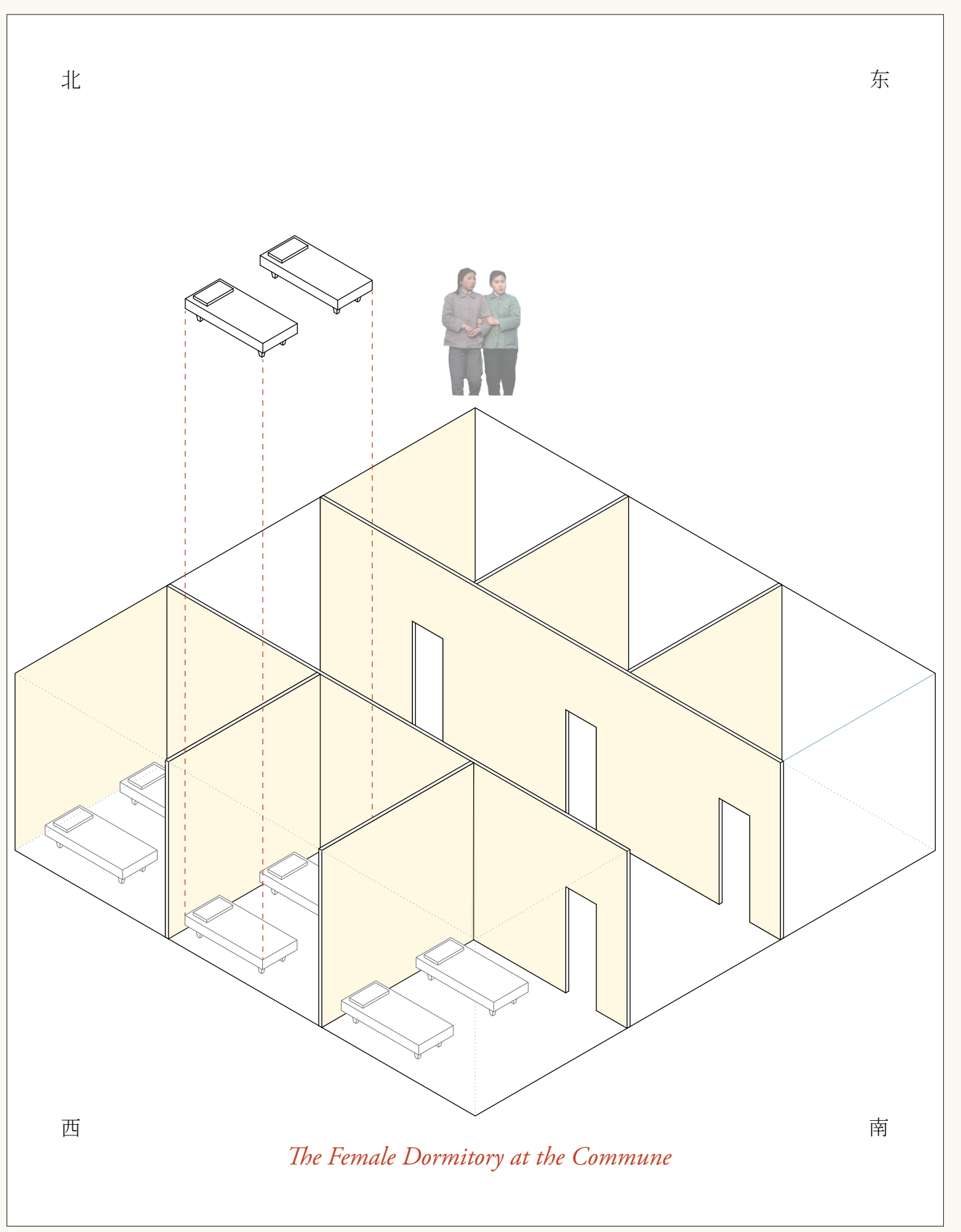

DURING

[FIGURE 3.16] A graphic axonometric emphasizing the lack of privacy and space within the commune, where few things are owned but a lot is shared. 
The housing industry transformed from a small-scaled artisan based operation into a highly systematized process based on new technological developments. Privacy became a luxury that many could not afford. With the standardization of residential buildings, basic design principles centred around economy, simplicity, and the industrialization of the construction process. This fast pace construction resulted in many poorly constructed buildings culminating in low quality living conditions. All ornamentation, both interior and exterior, were removed in an effort for the buildings to be more economic. Hierarchy within the living space was no longer present, families were sharing a one room apartment and unmarried individuals were rooming dormitory style with others of the same sex, although resistance in the separation was present and some would sneak around the dormitory. The promotion of a collectivized lifestyle was further enforced with the small size of the dorm rooms and apartments, the lack the space for individual privacy and other personal activities pushed people into the shared spaces in the commune and danwei. The unity and standardization of architecture was reflective of an overall unity in ideological stance, and commitment to the ideals of collectivization. 
The Bedroom

北

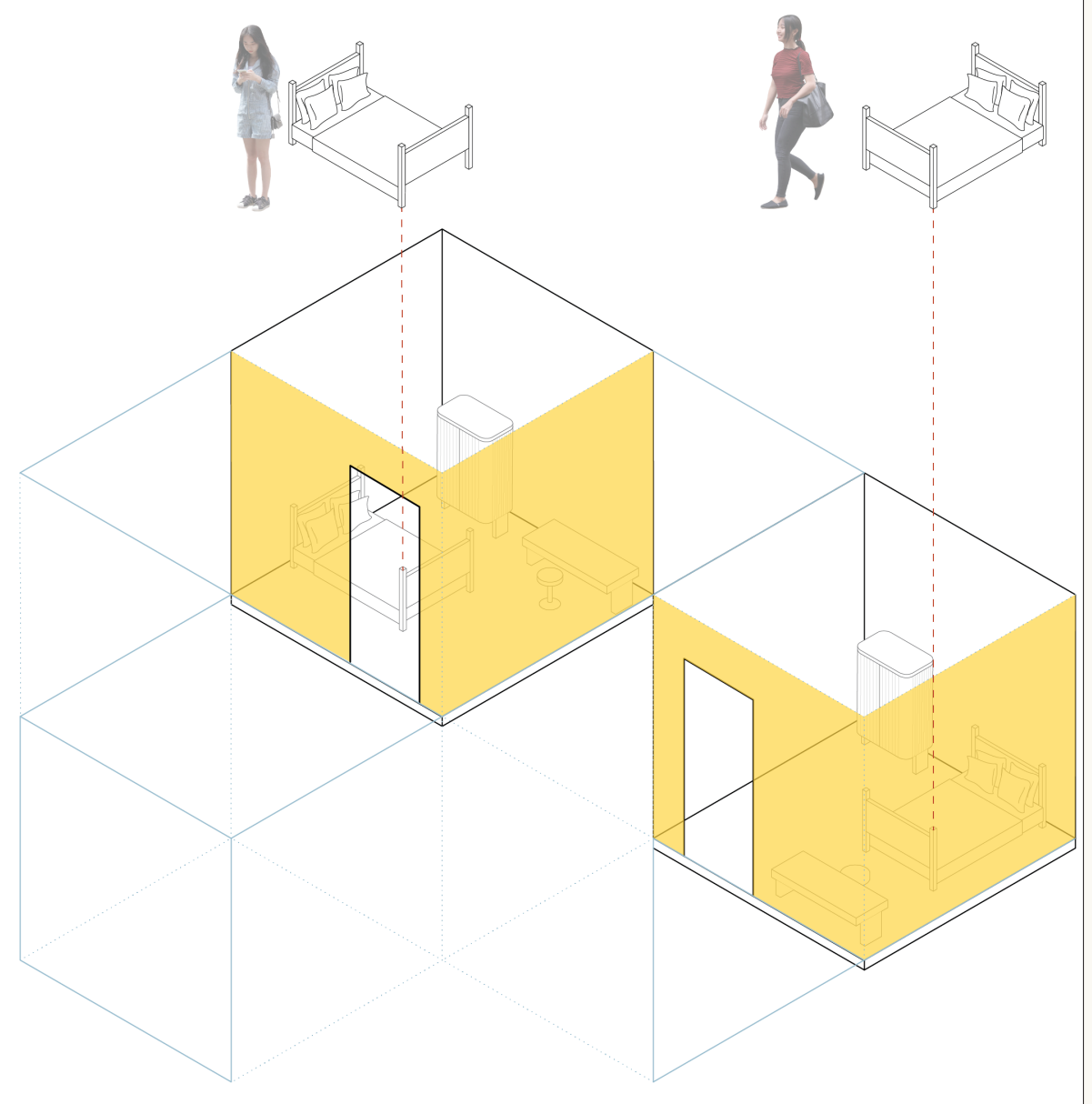

西

南

Roommates

[FIGURE 3.17] A graphic axonometric representative of a common type of living arrangement. The concept of living with a roommate is not new, however the choice to do so was not always available. 
The Bedroom

北

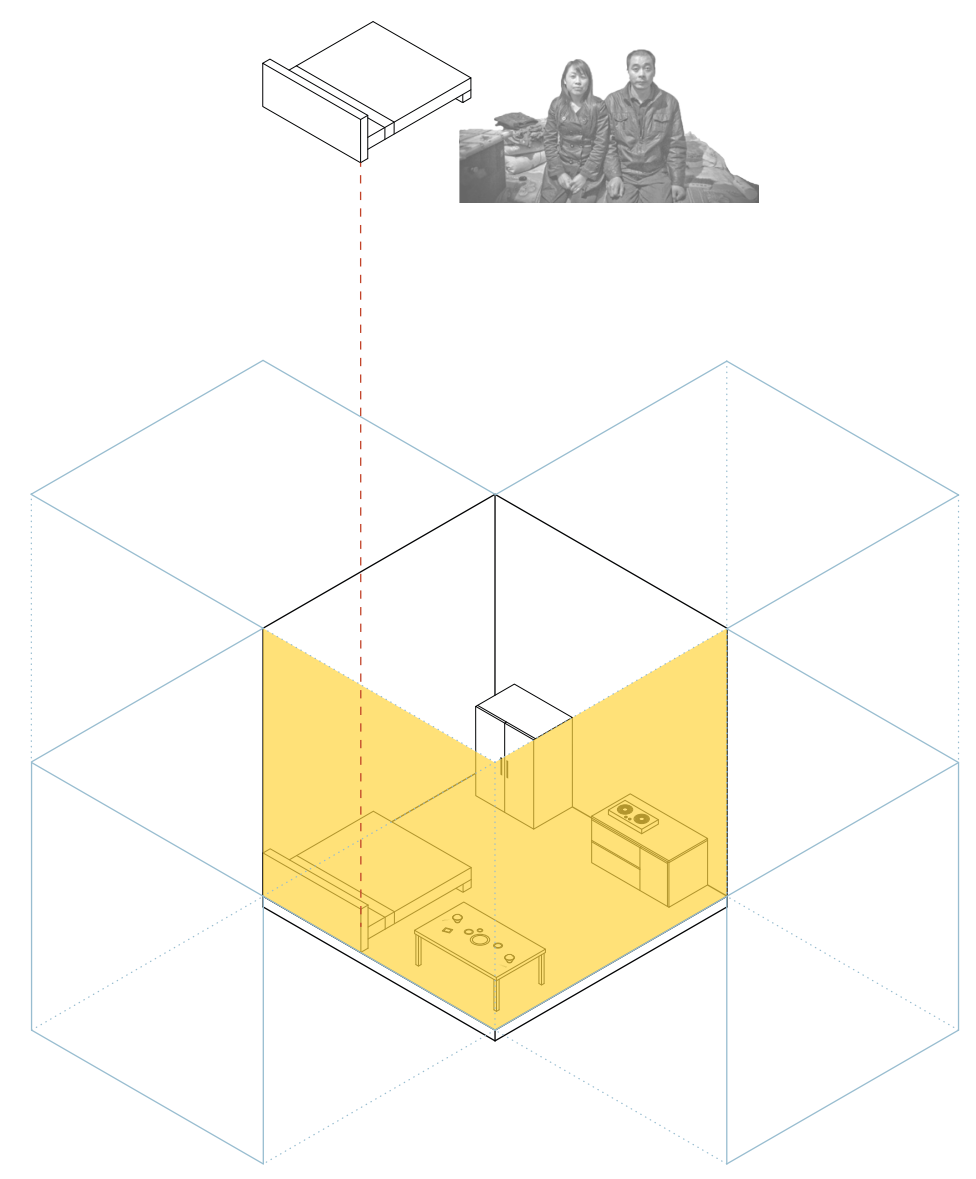

西

The Living and Dining Room

[FIGURE 3.18] A graphic axonometric representative of the lack of space many are facing, with no clear separation of hierarchies. 
The Bedroom

北

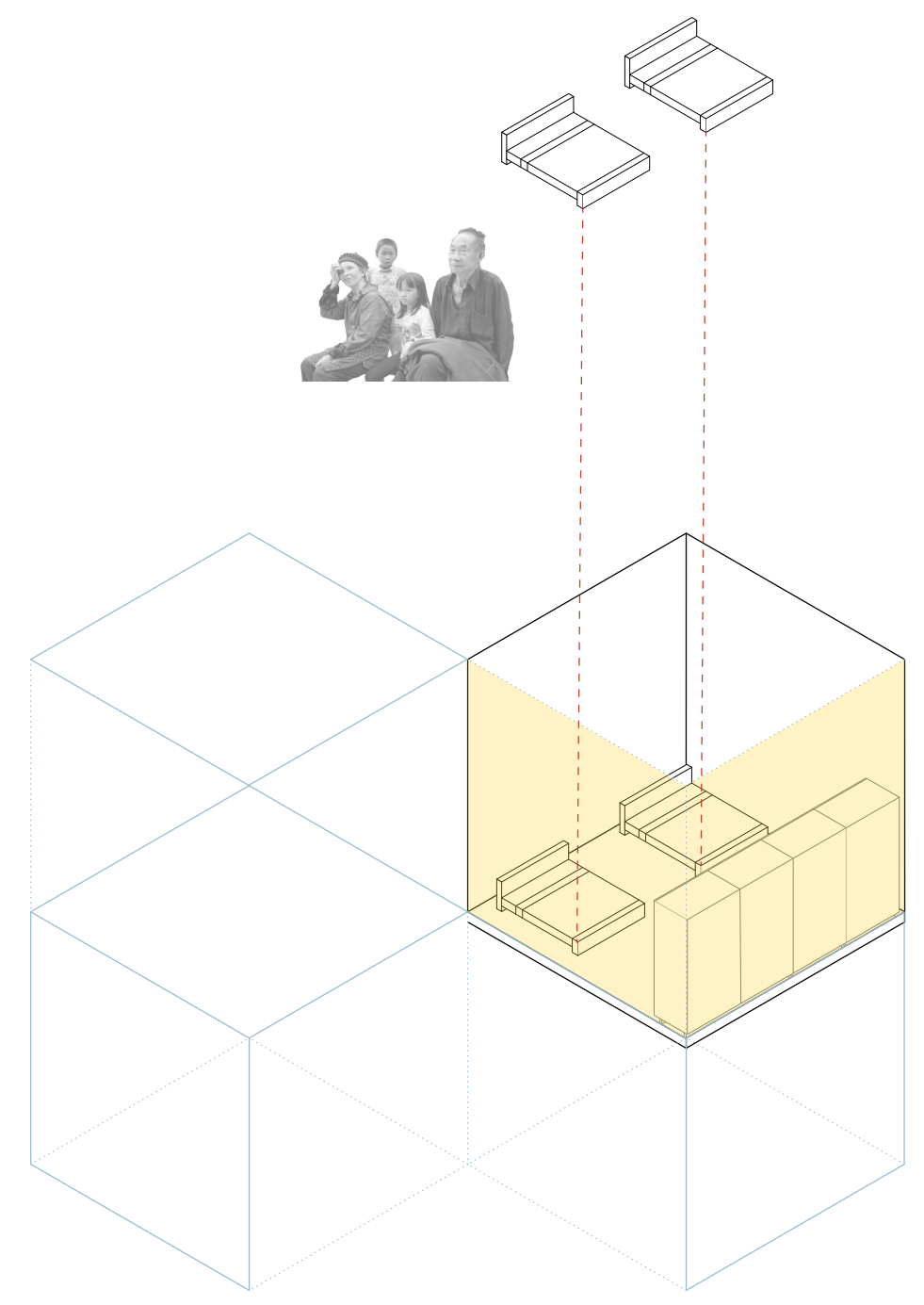

西

[FIGURE 3.19] A graphic axonometric representative of the space devoid of isolation, in which time become relative and life is lived through multiple lenses. 
The privatization of housing during the reform brought forth a variety of new living dynamics in modern China. Hierarchies of space and previous design principles of were no longer implemented in new housing constructions. Instead, efficiency of space was prioritized in order to adjust to the surge in market demand for urban housing. Following the basic construction of the commune and danwei residences, the bedroom remained primarily a single-purpose space, with a desk or vanity introduced in some cases. The bedroom became a highly private and intimate space with chores and entertaining guests taking place in the more public living rooms. However in terms of low income or temporary housing, the separation of the bedroom was considered a non-essential. The demand for housing created the incentive for the construction of residential apartments similarly to those found in the communes and danwei: a single room consisting of bedroom, living room, kitchen, and separate bathroom. These were constructed in many urban areas to accommodate the influx of migrant workers. At the same time, in many rural areas, the lack of infrastructure and finances forced multiple family members to sleep in a shared bedroom of the small family home. The multifaceted use of the bedroom have been reduced to the sole purpose of sleep, and the hierarchy of rooms based on sex were expelled. 


\section{The Bedroom}

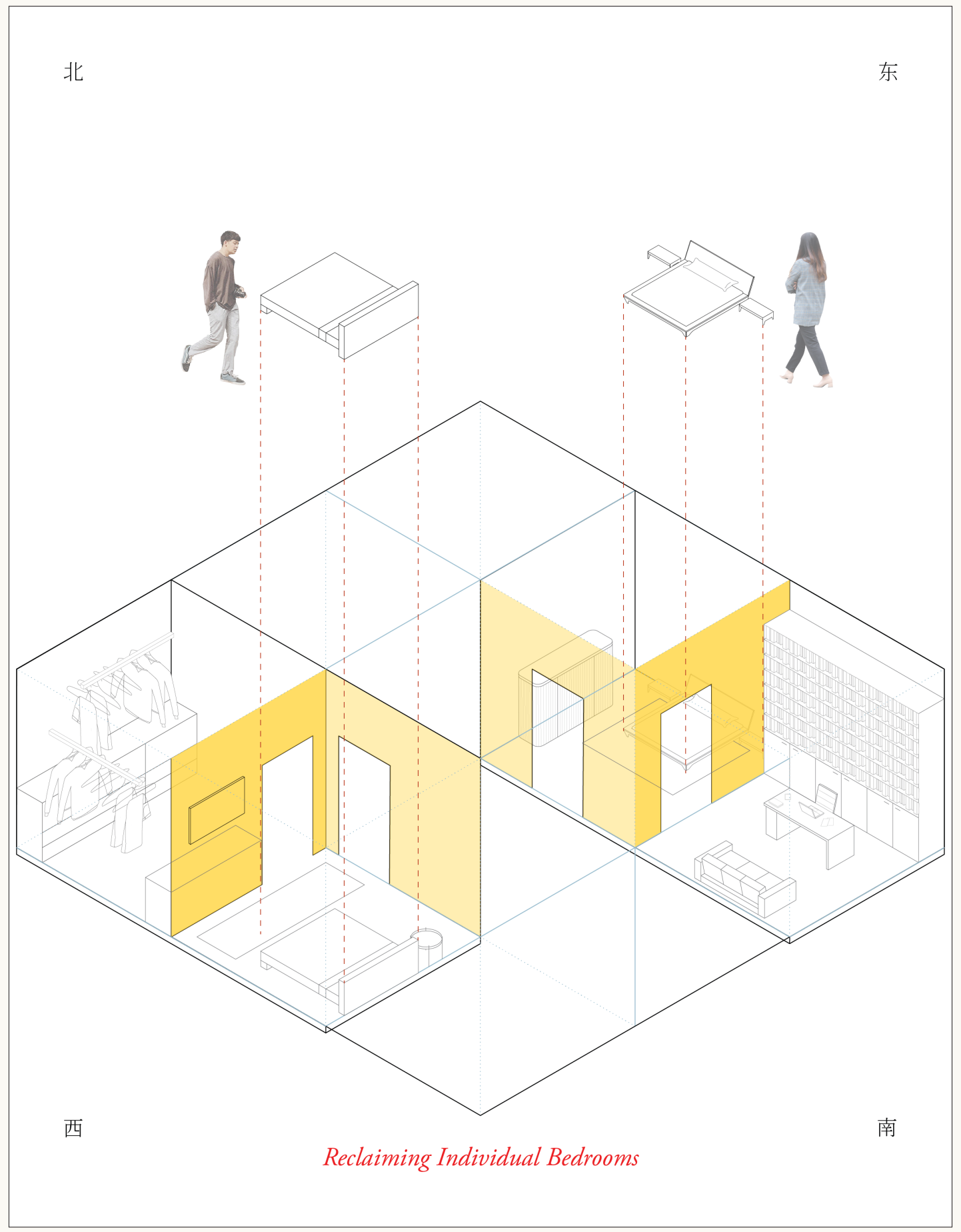

FUTURE

[FIGURE 3.20] A graphic axonometric representative a new type of residential space, a deliberate separation that reflects their individualism, rather than the forced seclusion of the past. 


\section{The Bedroom}

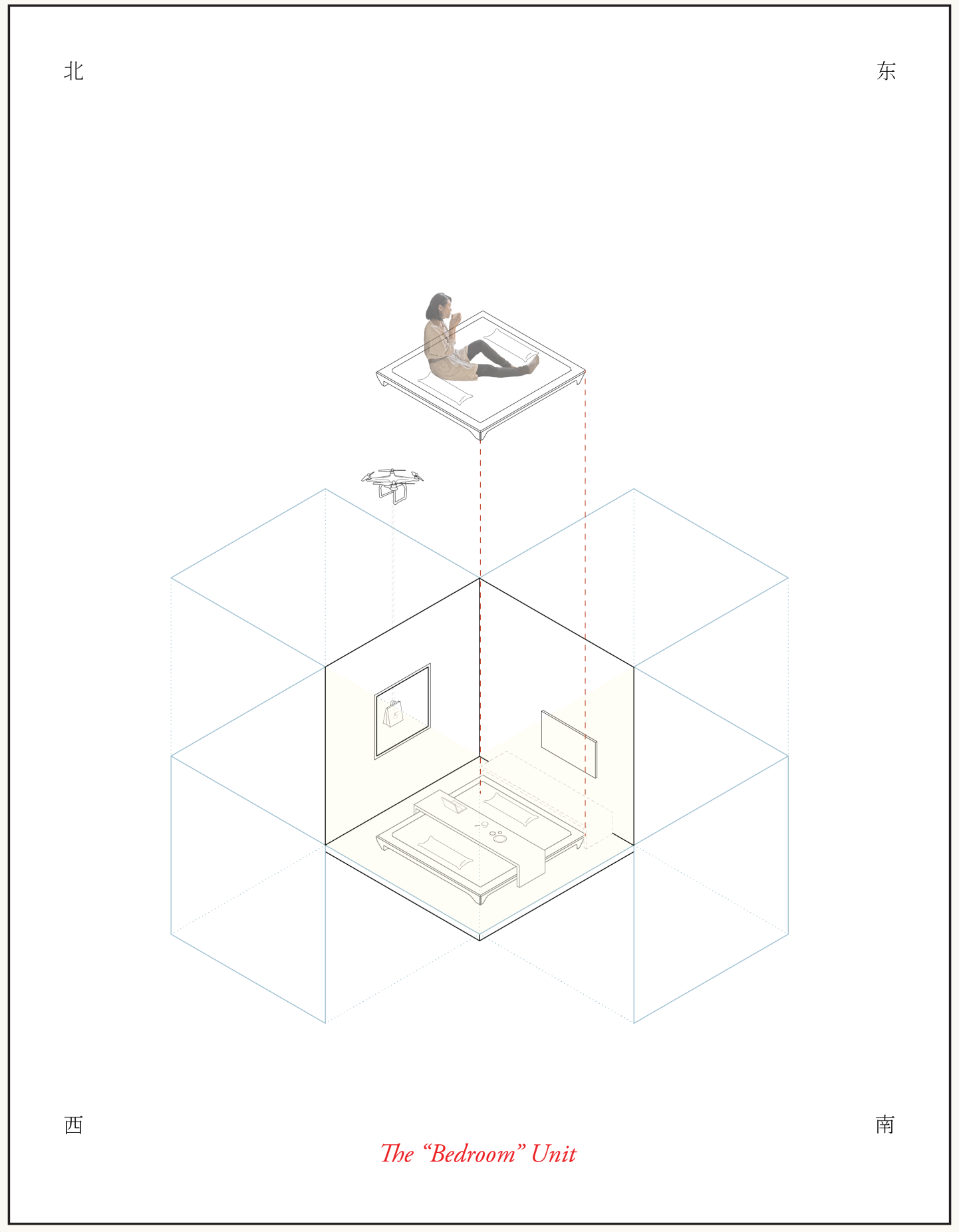

FUTURE

[FIGURE 3.21] A graphic axonometric which represents of a return to the utilization of the "bedroom" and a multi-use space. 
In this speculative future free from the sometimes restrictive philosophies of traditional Confucianism, as well as the controlling influence of Maoism, there is a common rejection of the traditional concept of a nuclear family as the only way of achieving success in life, particularly for females. People reject the old societal pressures to marry and raise a family, allowing each individual to define family in their own terms. Within this context, women can reclaim their bedroom as a separate space from their partners, with an attached private space, perhaps an office. Choosing to have a separation that reflects their individualism, rather than the forced seclusion of the past.

Or, owing once again to the continued population growth and dense urban conditions, people may redefine the bedroom as an open private space rather than an intimate private space. Lacking doors and walls, the space is open, serving as the dining room, bedroom, and spiritual room simultaneously. 


\section{CONCLUSION}

omestic architecture is intrinsically bound up with the socio-political and
cultural context within which it is designed and built. As a society experiences shifts in political or cultural ideology, the way people live and work shifts too, having varying degrees of impact on the way domestic space is constructed. Rather than passive or politically neutral, domestic architecture can in fact be the battleground on which policy and ideology is fought. In this thesis I have explored this condition in the context of twentieth century China, a time characterized by dramatic political upheaval and drastic cultural change. Through this study I have been able to gain a greater understanding of how political and cultural mechanisms passively impact or actively manipulate domestic space to achieve a certain goal.

Through the Mao-imposed Cultural Revolution in the mid-century, China went from a predominantly traditional Confusion society at the beginning of the nineteen hundreds, to a global economic power by the turn of the century. Mao Zedong was the central figure to this tumultuous age as he sought to reform China into a communist 
state. Significantly, Mao used his authoritarian power to dissolve the traditional family unit, redefine traditional hierarchies, and reshape traditional cultural rites and ceremonies, all through the dissolution of the traditional family home. This history reveals an oscillation of cause and effect between the political or cultural motivations of those in power and the organization, hierarchy, and meaning of space within domestic architecture. I have argued that this cause and effect is most perceptible in three key typological spaces within the home: spaces of prayer and reflection, spaces of dining, and the bedroom. By considering varying iterations of these spaces from three distinct eras of the past century, and comparing them to one another in a series of deliberate, systematically simplified drawings, I was able to effectively identify the multifarious, often subtle ways domestic space is reflective of, supportive of, or in direct resistance to shifts in major political and cultural philosophies.

In an attempt to synthesize the broader implications of my historical spatial analysis in order to extrapolate some conclusions in relation to contemporary practice, I devised a series of complimentary drawings exploring potential, speculative futures for spaces of prayer and reflection, dining, and the bedroom. Based on an imagined future condition, projected loosely from current socio-political trends, these drawings examine how domestic space might respond to or drive shifts in philosophical and ideological context. This exercise afforded me the opportunity to experiment with and better understand the implications of this cause and effect on the way we perceive and conceive space.

For the sake of clarity, the systematic analysis of domestic space I developed traces the evolution of each space from one era to the next following a linear cause and effect. While this simplicity was necessary to effectively discuss and interpret the complicated histories that surround the development of domestic space, I feel it is prudent to note that there are additional conclusions that can be proposed which suggests further cause and effect between the different spatial typologies. Recognizing 
the interconnectedness of these various spaces and their evolutions allows for a more nuanced understanding of the complex factors that implicate domestic architecture. Two cross-stream associations in particular are worth discussing in a little bit more detail due to their continued relevance in contemporary Chinese domestic architecture.

As I have previously explained, the bedroom in the traditional Chinese home was a space which served many more functions than merely sleep. Women and men, who each had their own bedroom, would use them for various daily activities. Women would attend to household chores such as mending clothes and cleaning, they would entertain guests, and sometimes even prepare meals. Men were more likely to read and study in their bedroom, and also entertain guests. When Mao's Communist Party established the system of communes across China as part of his mission to transform the nation into a communist state untethered from its traditional past, the function of the bedroom was dramatically reduced to the sole purpose of sleeping quarters. This shift not only affected the bedrooms of the post-Mao era, but also the spaces of prayer and reflection. In the communes the additional tasks once attended to in the bedroom were pushed out into other spaces throughout the complex. When the commune system was dismantled following Mao's death, and private dwellings were being built once again, the new idea of the bedroom stuck — they would be primarily for sleeping. Once again, the other traditional bedroom functions were pushed out into other areas of the home. Given the spatial demands of population growth, homes were necessarily compact, without room for superfluous space. As such, spaces of prayer and reflection could no longer occupy distinct spaces in the home and were, by necessity, absorbed into generic common rooms in which mending and cleaning, reading and studying, and entertaining took place, in addition to sleeping.

This thesis was born first out a personal desire to learn more about the complicated history of my native country, and second in an effort to introduce a study of Chinese vernacular architecture into popular Western discourse. During the 
course of my post-secondary education in architecture, I have been struck by the nearabsence of an Asian perspective in the history and theory of architecture that we are exposed to. While I understand that Canada has European roots and therefore Europe makes the most relevant precedent, I believe neglecting to explore more beyond the Eurocentric perspective is a missed opportunity at best. The intention of this thesis, in part, is to make an argument for greater exposure to the history and theory of Asian architecture. To that end, it was essential to make the very dense historical information and accompanying illustrative analysis as accessible as possible. The grid-based system of graphic representation afforded the work a sense of clarity and simplicity which rendered the analysis legible, while enabling more intricate observation to be overlaid. It is my hope that from my work, others will continue to explore the unique opportunities presented by a study of Asian architecture.

Beyond its academic aspirations, this thesis also resulted in the generation of more practical architectural implications. The close reading of architectural space in a domestic context, through tumultuous and sometimes traumatic era of political and cultural change, draws an awareness to domestic architecture as spaces which are capable of perpetuating certain political or cultural ideologies, or else driving change. As such it highlights the importance of deliberately and consciously reassessing contemporary spatial hierarchies that are employed in domestic architecture today and how they serve to perpetuate or subvert prevailing social norms. As architects, we are tasked with designing the spaces in which life takes place. We therefore have a responsibility to our clients and to society on the whole, not to be accessories of stagnancy and status-quo codification. This means recognizing the ways in which contemporary domestic typologies might uphold and preserve potentially outdated or even suppressive ideologies of identity, family, economy, and culture. The North American house today, for example, looks remarkably similar to those of the 1950s. Houses built at that time represented a very specific idea of Americana, characterized 
by the White, suburban nuclear family and its adherence to traditional gender roles. Today, the idea of family has expanded well beyond the picket fence, and the rejection of traditional gender roles has radically altered the way families operate. Yet the basic organization of the North American house remains stubbornly (nearly) unchanged. As a profession ostensibly dedicated to the thoughtful shaping of space, this thesis suggests we must critically rethink the impact even the most modest domestic architecture might have in reifying politically or culturally accepted 'norms,' in order to subvert them and enact meaningful change. 


\section{APPENDIX A}

Diagrammatic Timeline of China's Politics, Architecture, Housing, and Day to Day Life [1900-2000] 


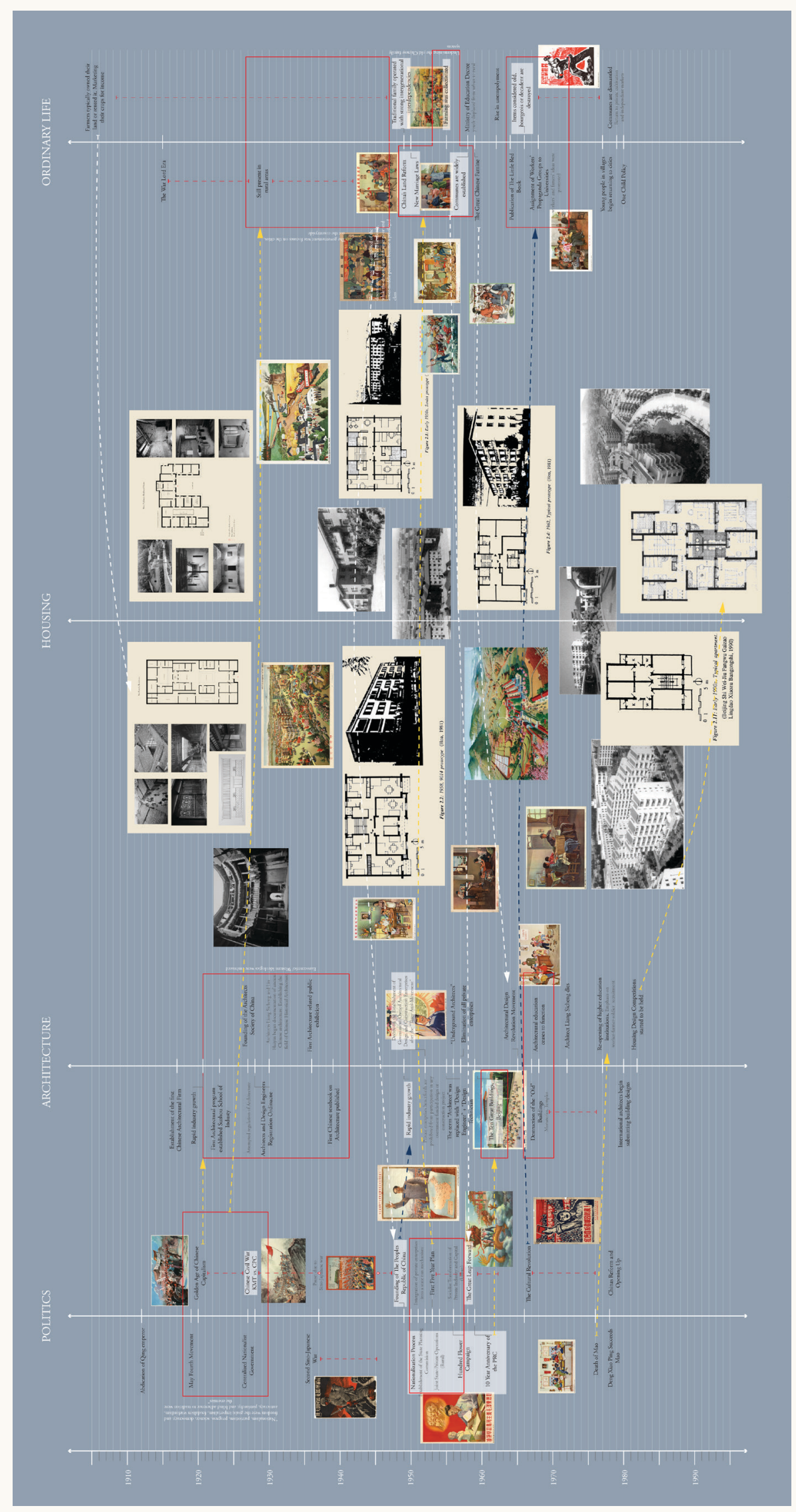




\section{IMAGE SOURCES}

[FIGURE 1.1] Source: Repoduced in Liu DunZhen, [A History of Classical Chinese Architecture, 1980]

[Figure 1.2] i 87 i City Map of LangZhong

[FIGURE 1.3] Source: Gong Kai, Shifen, Huizhou gu jianzhu congshu [Zhifeng Village Ancient Architecture in HuiZhou Series, 1999]

[Figure 1.4] Original Composition

[Figure 1.5] Original Composition

[FIGURE 1.6] Source: Repoduced in Fan Wei, [Village Fengshui Principles, 1992]

[Figure 1.7] Original Composition

FiguRE 1.8] Source: Wang Guodong: Official Portrait of Mao Zedong Public Domain

[FIGURE 1.9] Source: Huanan gongxueyuan jianzhuxi (1959) Guangdongsheng panyu renmin gongshe shaxu jumindian xinjian geti jianzhu sheji jieshao [An introduction to the design of new buildings in Shaxu Residential Cluster, Panyu People's Commune, Guangdong]. Jianzhu xuebao [Architectural Journal], No. 2 figure 13, p. 4.

[FIGURE 1.10] Wang, T. et al. (1958) Hebeisheng xushuixian suicheng renmin gongshe de guihua [The planning of Suicheng People's Commune, Xushui, Hebei]. Jianzhu xuebao [Architectural Journal], No. 11, figure 3, p. 15.

[[Figure 1.11] Source: Zhao, D. (1963) Beiyangcun shinyan xiaoqu guihua yu zhuzhai sheji [The planning and residential design of Beiyangcun experimental microdistrict]. Jianzhu xuebao [Architectural Journal], No. 3, figure 6, p. 2.

[Figure 1.12] @ Duanfang Lu.

[Figure 1.13] Source: Ye Zugi and Ye Zhoudu, "On Further Explorations into the Design of Small-Scale Residences, " [Journal of Architecture] 2 (1958:30-31)

[Figure 1.14] Designer Unknown, Source: https://chineseposters.net/posters/e13-856

[Figure 1.15] Public Domain

[Figure 1.16] @ Charlie Q.L. Xue

[Figure 1.17] @ Tim Franco

[Figure 1.18] Public Domain

[Figure 1.19] Source: OMA 
[Figure 1.20] Source: Qingling Zhang

[Figure 1.21] Source: Xinhua

[Figure 1.22] Source: Alarmy

[Figure 1.23] Source: Commune by the Great Wall

[Figure 1.24] @ Simon Song

[Figure 1.25] @ Thomas

[Figure 1.26] @ Bancroft

[Figure 1.27] Resources Center, School of Architecture, Tsinghual Qinghua Universit

[Figure 1.28] Source: Donia Zhang

[Figure 1.29] Source: People's Architecture Office

[Figure 2.1- Figure 3.21] Original Composition 
Blackburn, Simon. "Marxism.” In Oxford Reference, 2016. https://www-oxfordreference-com.proxy. library.carleton.ca/view/10.1093/acref/9780198735304.001.0001/acref-9780198735304e-1946?rskey=AP6j5q\&amp;result=1.

Boltz-Bornstein, Thorsten. "Wang Shu and the Possibilities of Architectural Regionalism in China." Nordic Journal of Architectural Research, 2009, 4-17.

Broudehoux, Anne-Marie. "Neighborhood Regeneration in Beijing: an Overview of Projects Implemented in the Inner City since 1990.” Thesis, McGill University, 1994.

Campbell, Charlie. “China: Why Xi Jinping May Have to Rule for Life.” Time. March 12, 2018. https://time.com/5195211/china-xi-jinping-presidential-term-limits-npc/.

Carlson, Jack. “China’s Copycat Cities.” Foreign Policy, November 29, 2012. https://foreignpolicy.com/2012/11/29/chinas-copycat-cities/.

Colombia University. “The Commune System (1950s).” Asia for Educators. Accessed March 20, 2021. http://afe.easia.columbia.edu/special/china_1950_commune.htm.

“Comitern.” In Collins Dictionary. Accessed November 30, 2020. https://www.collinsdictionary.com/dictionary/english/comintern.

Cook, Alexander C, ed. Mao's Little Red Book: A Global History. Cambridge: Cambridge University Press, 2014.

Ding, Guanghui. Constructing a Place of Critical Architecture in China: Intermediate Criticality in the Journal Time + Architecture. New York, NY: Ashgate Publishing, 2015.

Ding, Guanghui. “'Experimental Architecture' in China." Journal of the Society of Architectural Historians 73, no. 1 (March 2014): 28-37. https://doi.org/10.1525/jsah.2014.73.1.28.

Eberhard, Wolfram. A History of China. Berkeley and Los Angeles, CA: University of California Press, 1950.

Ebrey, Patricia Buckley. "House Architecture.” A Visual Sourcebook o Chinese Civilization. University of Washington. Accessed February 2, 2021. https://depts.washington.edu/chinaciv/ home/3intrhme.htm.

Ebrey, Patricia Buckley. The Cambridge Illustrated History of China. Seconded. New York, NY: 
Cambridge University Press, 2010.

Endicott, Stephen Lyon. Red Earth: Revolution in a Sichuan Village. New York, NY: New Amsterdam, 1991.

Gallagher, Mary. “Does a Stronger Xi Mean a Weaker Chinese Communist Party?” The New York Times. The New York Times, March 2, 2018. https://www.nytimes.com/2018/03/02/ opinion/xi-jinping-china.html.

Handler, Richard. "Authenticity." Anthropology Today 2, no. 1 (1986): 2. https://doi. org/10.2307/3032899.

Hickman, Matt. "China to Crack down on Copycat Architecture." The Architect's Newspaper, May 12, 2020. https://www.archpaper.com/2020/05/china-to-crack-down-on-copycat-architecture/.

Howden, David, and Yang Zhou. "Why Did China’s Population Grow so Quickly? .” The Independent Review 20, no. 2 (2015): 227-48.

Huang, Shu-min. The Spiral Road: Change in a Chinese Village through the Eyes of a Communist Party Leader. Westview Press, 1998.

Kagitçibasi Çigdem. "Individualism and Collectivism.” Essay. In Handbook of Cross-Cultural Psychology. Social Behavior and Applications 3, Seconded., 3:1-49. Boston: Allyn and Bacon, 1997.

Knapp, Ronald G. China’s Living Houses: Folk Beliefs, Symbols, and Household Ornamentation. Honolulu, HI: University of Hawaii Press, 1999.

Knapp, Ronald G. China's Old Dwellings. Honolulu, HI: University of Hawaii Press, 2000.

Knapp, Ronald G. China's Traditional Rural Architecture: a Cultural Geography of the Common House. Honolulu, HI: University of Hawaii Press, 1986.

Knapp, Ronald G. Chinese Houses: the Architectural Heritage of a Nation. Tuttle, 2005.

Lee, Yun Kuen. "Building the Chronology of Early Chinese History." Asian Perspectives 41, no. 1 (2002): 15-42.

Lewis, Martin W, and Wigen Kären. The Myth of Continents: a Critique of Metageography. Berkeley, CA: University of California press, 1997.

Li, Gucheng. "Si Jiu." Essay. In A Glossary of Political Terms of the People's Republic of China, 426-28. 
Hong Kong: The Chinese University Press, 1995.

Liang, Sicheng. A Pictorial History of Chinese Architecture: a Study of the Development of Its Structural System and the Evolution of Its Types. Cambridge, MA: MIT Press, 1984.

Lu, Andong, and Pingping Dou. China Homegrown: Chinese Experimental Architecture Reborn. Oxford: John Wiley \&amp; Sons, 2018.

Lu, Duanfang. Remaking Chinese Urban Form Modernity, Scarcity and Space, 1949-2005.

Abingdon: Routledge, 2011.

Needham, Joseph, Wang Ling, and Gwei-Djen Lu. Science and Civilisation in China. 4. Vol. 4. London: Cambridge University Press, 1971.

“Overlooked No More: Lin Huiyin and Liang Sicheng, Chroniclers of Chinese Architecture.” The New York Times. The New York Times, April 12, 2018. https:/www.nytimes.com/2018/04/11/ obituaries/overlooked-lin-huiyin-and-liang-sicheng.html.

Qijun, Wang. Vernacular Dwellings: Ancient Chinese Architecture. New York, NY: Springer, 2000.

Qun Rene, Chen. “Cardinal Directions In Chinese Language: Their Cultural, Social And Symbolic Meanings.” ETC: A Review of General Semantics 66, no. 2 (2009): 225-39.

Riches, Christopher, and Jan Palmowski. “Maosim.” In Oxford Reference, 2019. https:// www-oxfordreference-com.proxy.library.carleton.ca/view/10.1093/ acref/9780191870903.001.0001/acref-9780191870903-e-1468?rskey=4GM5Tc\&amp;res ult $=1672$.

Rousseau, Jean-Jacques, and Henry John Tozer. “Book One.” Essay. In The Social Contract, 5-22. Ware, HRT: Wordsworth, 1998.

Sixth Tone. "Saving China's Soul, One Village at a Time." Sixth Tone, February 7, 2018. http://www. sixthtone.com/news/1001685/saving-chinas-soul,-one-village-at-a-time.

"Standing Their Ground." Amnesty International. Peter Benenson House, 2012. Amnesty International. https://www.amnesty.org/download/Documents/20000/asa170012012en.pdf.

Steinhardt, Nancy Shatzman. Chinese Architectural History in the Twenty-First Century. University of California Press, 2014.

Tao, Zhu. "Building Big, With No Regret:” AA Files 63 (2011): 104-10. 
Theodore, De Bary Wm., Wing-tsit Chan, Burton Watson, and Yibao Mei. Sources of Chinese Tradition. New York, NY: Columbia University Press, 1960.

Triandis, Harry C. "Individualism-Collectivism and Personality.” Journal of Personality 69, no. 6 (2001): 907-24. https://doi.org/10.1111/1467-6494.696169.

Waley, Arthur. The Way and Its Power: A Study of the Tao Te Ching and Its Place in Chinese Thought. New York, NY: Grove Press, 1958.

Walsh, Bettye S., and Howard Giskin. An Introduction to Chinese Culture Through the Family. Albany: State University of New York Press, 2001.

Wang, Bing. "Structuring of the Architectural Profession in Modern China," Thesis, Harvard University. 2004.

Wang, Ye Ping, and Alan Murie. "The Process of Commercialization of Urban Housing in China." Urban Studies 33, no. 6 (1996): 271-88.

Xue, Charlie Q. Building a Revolution: Chinese Architecture since 1980. Hong Kong: Hong Kong University Press, 2006.

Yao, Xinzhong. “Confucian Studies East and West.” Introduction. In An Introduction to Confucianism, 1-15. Cambridge: Cambridge Univ. Press, 2008.

Yi, Zeng, Zhang Chungyan, Peng Songjian, and Ma X. "Changes in Family and Population Reproductions in China.” Essay. In Changing Family Structure and Population Aging in China, 58-81. Beijing: Peking University Press, 1990.

Zeng, Yi, and Therese Hesketh. "The Effects of China's Universal Two-Child Policy.” Lancet (London, England). U.S. National Library of Medicine, October 15, 2016. https://www.ncbi.nlm. nih.gov/pmc/articles/PMC5944611/.

Zhiping, Liu. A Brief History of Chinese Residential Architecture (City, Residence, Garden) / Zhongguo Ju Zhu Jian Zhu Jian Shi: Cheng Shi, Zhu Zhai, Yuan Lin. Beijing, BJ: China Construction Industry Press / Zhongguo jian zhu gong ye chu ban she, 1990.

Zhu, Jianfei. Architecture of Modern China: a Historical Critique. London: Routledge, 2009.

Zuo, Jiping. "Political Religion: The Case of the Cultural Revolution in China." Sociological Analysis 52, no. 1 (1991): 99-110. https://doi.org/10.2307/3710718. 
Thank you. 